\title{
Property Changes of G347A Graphite Due to Neutron Irradiation ${ }^{\#}$
}

\author{
Anne A. Campbell ${ }^{a, *}$, Yutai $\operatorname{Katoh}^{a}$, and Mary A. $\operatorname{Snead}^{a}$, Kentaro Takizawa ${ }^{\mathrm{b}}$ \\ ${ }^{a}$ Oak Ridge National Laboratory, Oak Ridge, TN 37831 \\ ${ }^{\mathrm{b}}$ Tokai Carbon Co., Ltd., Japan
}

\begin{abstract}
A new, fine-grain nuclear graphite, grade G347A from Tokai Carbon Co., Ltd., has been irradiated in the High Flux Isotope Reactor at Oak Ridge National Laboratory to study the materials property changes that occur when exposed to neutron irradiation at temperatures of interest for Generation-IV nuclear reactor applications. Specimen temperatures ranged from $290^{\circ} \mathrm{C}-800^{\circ} \mathrm{C}$ with a maximum neutron fluence of $40 \times 10^{25} \mathrm{n} / \mathrm{m}^{2}$ [E>0.1MeV] ( 30dpa). Observed behaviors include: anisotropic behavior of dimensional change in an isotropic graphite, Young's modulus showing parabolic fluence dependence, electrical resistivity increasing at low fluence and additional increase at high fluence, thermal conductivity rapidly decreasing at low fluence followed by continued degradation, and a similar plateau value of the mean coefficient of thermal expansion for all irradiation temperatures.
\end{abstract}

\section{INTRODUCTION}

Graphite has been readily used in nuclear reactors since the first controlled nuclear chain reaction. Graphite has a low atomic number and low neutron cross-section, making it an ideal neutron moderator. Additionally, the high strength, high thermal stability, and high thermal conductivity make graphite an ideal structural material. But, in the presence of neutron radiation these properties are changed [1-16], and these changes depend upon the temperature of the graphite during exposure to neutrons.

Typical property changes include the initial densification to a maximum density, followed by swelling until the material loses all structural integrity $[3,5-9,12,16]$. Typically dimensional changes are anisotropic resulting from the preferred orientation of the grains with irradiation causing grains to grow in the c-direction and shrink in the a-direction $[9,12,13]$. The elastic moduli have been shown to undergo a rapid rise, followed by a gradual increase to a peak value, followed by a decrease as the swelling becomes positive $[1,3,6,7,9,12,13,15]$. Conversely, the electrical resistivity has been observed to rapidly rise with low fluence and holds at an elevated value for higher fluence [1, 3, 7, 12]. Strength has been shown to have a one-to-one or a square root dependence on Young's modulus change $[1,6,7,9,12,13,15]$. The thermal conductivity displays behaviors that mirror the electrical resistivity, where it rapidly

\footnotetext{
\#This manuscript has been authored by UT-Battelle, LLC under Contract No. DE-AC05-00OR22725 with the U.S. Department of Energy. The United States Government retains and the publisher, by accepting the article for publication, acknowledges that the United States Government retains a nonexclusive, paid-up, irrevocable, worldwide license to publish or reproduce the published form of this manuscript, or allow others to do so, for United States Government purposes. The Department of Energy will provide public access to these results of federally sponsored research in accordance with the DOE Public Access Plan (http://energy.gov/downloads/doe-publicaccess-plan).

*Corresponding author: A.A. Campbell, Tel: +1-865-576-5463. E-mail: campbellaa@ornl.gov
} 
decreases and then remains nearly constant $[1,3,6,7,12,15]$. The thermal expansion undergoes a rapid increase, followed by a decrease to a plateau value that is lower than the preliminary value $[3,5,7,9,12]$.

The earliest graphite grades employed in the nuclear industry were grades that were initially used as electrodes, but had undergone additional purification. These grades were manufactured with naturally occurring graphite deposits as the coke source, but the finite supply means that only a limited amount of a given grade could be manufactured. Much of the early research into the irradiation effects was primarily focused on these early grades. With these works it was noticed that the properties underwent changes with similar trends, but were not identical between grades. This lack of uniform response has resulted in every new grade of nuclear graphite requiring extensive irradiation campaigns to fully understand the property changes.

This paper presents the results of an irradiation campaign performed in the High Flux Isotope Reactor (HFIR) at Oak Ridge National Laboratory (ORNL) to investigate the neutron irradiation effects on a new fine-grain, isomolded, graphite grade: G347A from Tokai Carbon Co., Ltd. The property changes investigated include: volume/dimensional, elastic and shear moduli, electrical resistivity, equibiaxial (ring-on-ring) strength, thermal conductivity, and the coefficient of thermal expansion (CTE).

\section{EXPERIMENTAL}

\subsection{GRAPHITE GRADE}

This program was primarily focused on the effects of irradiation on Tokai Carbon Co., Ltd. graphite grade G347A, but some limited investigation was also performed on another grade (G458A) from the same manufacturer. G347A has a coal coke filler while G458A has petroleum coke filler, but both G347A and G458A have a pitch binder, pitch for impregnation, and are formed via cold isostatic pressing The ORNLmeasured and the manufacturer-reported bulk properties for these two grades are listed in Table 1. For the ORNL-measured values, the reported values are the average \pm one standard deviation, and the numbers in () are the number of specimens measured to obtain the statistics. There was limited ORNL investigation into the properties of G458A, hence why the reported values from ORNL measurements is limited. All of the ORNL-measured properties were obtained according to the requirements stated in the various ASTM standards, which are also listed in Table 1. According to the requirements of ASTM D7219 [17], G347A falls in the grade category of "Isomolded, Isotropic - High Purity". Since both G347A and G458A are isostatically-molded grades, the traditional orientations of With Grain and Against Grain are not suitable to identify the two different directions in this material. Instead, the direction used for reference is the dimension of the billet that is vertical during the molding process (parallel to gravity), which will be referred to as the axial direction (AX), and the two other orthogonal directions are referred to as the transverse directions (TR). Five different specimen shapes were machined for irradiation. Table 2 summarizes the specimen shapes, orientations, dimensions, and measurements performed.

Table 1. Summary of bulk pre-irradiation properties of graphite grades both measured by ORNL, the properties reported by the manufacturer, and the corresponding ASTM standard used by ORNL for property measurement. The ORNL results are the average \pm 1 standard deviation followed by the number of specimens used for each measurement in (). 


\begin{tabular}{|c|c|c|c|c|c|}
\hline & $\begin{array}{l}\text { ORNL measured } \\
\text { values G347A }\end{array}$ & $\begin{array}{c}\text { Tokai } \\
\text { Reported } \\
\text { Values } \\
\text { G347A } \\
\end{array}$ & $\begin{array}{l}\text { ORNL measured } \\
\text { values G458A }\end{array}$ & $\begin{array}{c}\text { Tokai } \\
\text { Reported } \\
\text { Values } \\
\text { G458A } \\
\end{array}$ & $\begin{array}{l}\text { ASTM } \\
\text { Standard }\end{array}$ \\
\hline Density $\left(\mathrm{g} / \mathrm{cm}^{3}\right)$ & $1.84 \pm 0.01(335)$ & 1.85 & $1.84 \pm 0.02(24)$ & 1.86 & $\begin{array}{l}\text { C559-90 [18] } \\
\text { C838-96 [19] }\end{array}$ \\
\hline Young's Modulus (GPa) & $\begin{array}{c}11.13 \pm 0.49 \text { TR }(74) \\
10.72 \pm 0.46 \text { AX }(126) \\
\end{array}$ & 10.8 & $11.29 \pm 1.24 \mathrm{AX}(6)$ & 11.3 & C1259-14 [20] \\
\hline Shear Modulus (GPa) & $\begin{array}{l}4.23 \pm 0.03 \text { TR (10) } \\
4.15 \pm 0.06 \text { AX }(60)\end{array}$ & & & & C1259-14 [20] \\
\hline Poisson's Ratio & $\begin{array}{l}0.27 \pm 0.01 \text { TR }(10) \\
0.24 \pm 0.01 \text { AX }(60)\end{array}$ & & & & C1259-14 [20] \\
\hline $\begin{array}{l}\text { Mean Coefficient of Thermal } \\
\text { Expansion }\left(\times 10^{-6} /{ }^{\circ} \mathrm{C}\right)\end{array}$ & $\begin{array}{l}4.18 \pm 0.05 \mathrm{TR}^{\mathrm{a}}(6) \\
4.48 \pm 0.02 \mathrm{AX}^{\mathrm{a}}(6) \\
\end{array}$ & 5.5 & $3.81 \pm 0.02 \mathrm{AX}^{\mathrm{a}}(3)$ & 4.4 & E228-11 [21] \\
\hline $\begin{array}{l}\text { Thermal Conductivity } \\
\text { @ } 25^{\circ} \mathrm{C}(\mathrm{W} / \mathrm{mK})\end{array}$ & $\begin{array}{l}156.88 \pm 3.62 \text { TR }(6) \\
148.15 \pm 3.72 \text { AX }(6)\end{array}$ & 128 & $134.6 \pm 6.23 \mathrm{AX}(6)$ & 139 & E1461-13 [22] \\
\hline Electrical Resistivity $(\mu \Omega \mathrm{m})$ & $\begin{array}{c}9.1 \pm 0.03 \text { TR }(10) \\
9.53 \pm 0.11 \text { AX }(60)\end{array}$ & 11.0 & & 9.5 & C611-98 [23] \\
\hline Tensile Strength (MPa) & & 31.4 & & 35.3 & \\
\hline Flexural Strength (MPa) & & 49.0 & & 53.9 & \\
\hline Equibiaxial Strength (MPa) & $59.79 \pm 3.12$ TR $(61)$ & & & & C1499-05 [24] \\
\hline Anisotropy Ratio & 1.07 & & & & D7219 [17] \\
\hline Max Grain Size (mm) & & 0.05 & & 0.05 & \\
\hline
\end{tabular}

Table 2. Summary of specimen types, dimensions, and measurement performed before and after irradiation.

\begin{tabular}{|c|c|c|c|}
\hline $\begin{array}{c}\text { Dimensions } \\
(\mathbf{m m})\end{array}$ & $\begin{array}{l}\text { Specimen Shape } \\
\text { Designator }\end{array}$ & Orientation & Measurements \\
\hline $25 \times 2.9 \times 2.4$ & SB-W3 & $25 \mathrm{~mm}$ in $\mathrm{AX}$ and $\mathrm{TR}$ & Density, Young's modulus, CTE \\
\hline $30 \times 3.8 \times 2.9$ & SB-W4 & $30 \mathrm{~mm}$ in $\mathrm{AX}$ and $\mathrm{TR}$ & Density, Young's modulus, Electrical resistivity, CTE \\
\hline $48 \times 6 \times 1$ & MB-W6 & $48 \mathrm{~mm}$ in AX only & Density, Young's modulus, Shear modulus \\
\hline$\emptyset 6 \times 4.8$ & TD-D6 & 4.8mm in AX and TR & Density, Thermal conductivity \\
\hline $6 \times 6 \times 0.5$ & SQ6 & $0.5 \mathrm{~mm}$ in AX only & Equibiaxial strength \\
\hline
\end{tabular}

\subsection{PROPERTIES INVESTIGATED}

The non-destructive properties (density, dynamic modulus, and electrical resistivity) were measured on each specimen before irradiation, which enabled direct comparison of properties before and after irradiation. The high-temperature thermal properties (CTE and thermal conductivity) were performed on a subset of the specimens not slated for irradiation. This practice is to prevent any changes to specimens slated for irradiation since an unintended oxygen leak into either system would result in mass loss of the specimens, thereby changing the other physical properties. The equibiaxial strength destructive measurements were also performed on a sub-set of the specimens that would not be irradiated. The investigation of these changes will allow for an understanding of whether the materials properties of this fine-grained graphite respond differently than medium- or coarse-grained graphite when exposed to neutron irradiation. Additionally, this work provides preliminary results of the property changes of this grade that can be used by reactor designers in planning high-temperature gas reactors and molten salt reactors. 
All the properties were measured according to the ASTM standards for either graphite or advanced ceramics. Density was determined according to ASTM C559-90 and C838-96 [18, 19]. The moduli were determined via the impulse excitation resonance methodologies, described in ASTM standard C1259-14 [20], using the Integrated Material Control Engineering (IMCE) Resonant Frequency and Damping Analyzer (RFDA). The electrical resistivity was determined according to ASTM C611-98 [23], using a specially machined sample holder for 4-point probe setup with $25 \mathrm{~mm}$ probe spacing and a Keithley Source meter and Keithley Nano-voltmeter. The CTE was determined in accordance with ASTM E22811 [21], and utilized a NETZSCH model 402CD pushrod dilatometer with a continuous heating and cooling rate of $3^{\circ} \mathrm{C} / \mathrm{min}$, and a titanium-gettered helium environment. The thermal conductivity was determined from the thermal diffusivity measurements according to ASTM E1461-13 [22], in a NETZSCH LFA 457 MicroFlash Laser Flash Thermal Diffusivity Apparatus. The equibiaxial strength measurements were performed according to ASTM C1499-05 [24], with a MTS Insight-10 test frame equipped with a $1 \mathrm{kN}$ load cell, a crosshead rate of $1 \mathrm{~mm} / \mathrm{min}$, a support ring with $5 \mathrm{~mm}$ diameter torus with $0.5 \mathrm{~mm}$ minor radius, and load ring $2 \mathrm{~mm}$ diameter torus with $0.5 \mathrm{~mm}$ minor radius.

\subsection{IRRADIATION INFORMATION}

The irradiations were performed in the ORNL HFIR. The HFIR is an $85 \mathrm{MW}$ pressurized water reactor that has a typical cycle length of 25 days. The specimens were assembled in specially designed irradiation capsules (called rabbits), and irradiation of the rabbits occurred in the HFIR flux trap. The neutron flux range was $0.9-1.1 \times 10^{19} \mathrm{n} / \mathrm{m}^{2} / \mathrm{s}[\mathrm{E}>0.1 \mathrm{MeV}]$, and the exact flux was dependent on the axial and radial location of the rabbits. The HFIR cycle begins with a rapid power rise to $85 \mathrm{MW}$ (on the order of a few minutes), the power is kept constant at $85 \mathrm{MW}$, and when power can no longer be maintained the reactor is rapidly shutdown (on the order of a few seconds). The cycle length results in an accumulated neutron fluence of $1.9-2.4 \times 10^{25} \mathrm{n} / \mathrm{m}^{2}[\mathrm{E}>0.1 \mathrm{MeV}]$ per cycle $(1.3-1.7 \mathrm{dpa} /$ cycle), so the highest damage rabbit ( $\sim 30 \mathrm{dpa}$ ) was in the HFIR for 18 cycles. The rabbits consist of an outer aluminum housing and an inner specimen holder (machined from $\mathrm{V}-4 \mathrm{Cr}-4 \mathrm{Ti}$ or $\mathrm{Nb}-1 \mathrm{Zr}$ ), with a gas gap between the housing and holder. Two different specimen configurations were utilized in this work, referred to as GRIC-1 and GRIC-2. The specimen types irradiated in each rabbit are listed in Table 3. These capsules have no active temperature measurement or control due to space limitations. Instead the width of the gas gap, and the insulating gas (argon, neon, or helium), were iteratively determined via two-dimensional heat transfer calculations to achieve the desired specimen temperature. Mid-way though the irradiation program, the ability to model the rabbits in three-dimensions became available. Thus the capsules were re-modeled with the 3D ANSYS software for more accurate specimen temperature determination. An example of the specimen configurations and the specimen temperature profiles for a target specimen temperature of $450^{\circ} \mathrm{C}$ are shown in Figure 1.

Table 3. Summary of graphite grades and specimen types utilized in the two rabbit configurations.

\begin{tabular}{|c|c|c|c|c|c|c|c|}
\hline \multirow{2}{*}{$\begin{array}{c}\text { Rabbit } \\
\text { Type }\end{array}$} & \multirow{2}{*}{ Graphite Grade } & \multicolumn{6}{|c|}{ Specimen Type } \\
\hline & & SB-W3 & SB-W4 & MB-W6 & TD-D6 & 5SQ6 & 4SQ6 \\
\hline GRIC-1 & G347A & & 2 & 1 & 3 & $2^{\mathrm{a}}$ & \\
\hline GRIC-2 & G347A \& G458A & 4 & & & 4 & & $2^{\mathrm{b}}$ \\
\hline
\end{tabular}




\footnotetext{
${ }^{\mathrm{b}} 8$ total SQ6 coupons, held together in two larger specimens composed of 4 6x6x0.5 mm specimens $(24 \times 6 \times 0.5$ $\mathrm{mm}$ total specimen dimension)
}

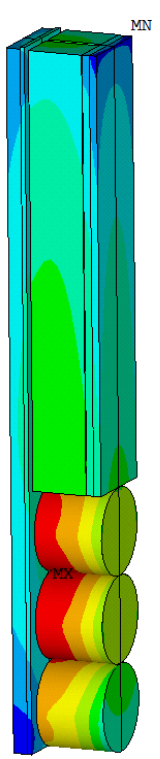

GRIC-1
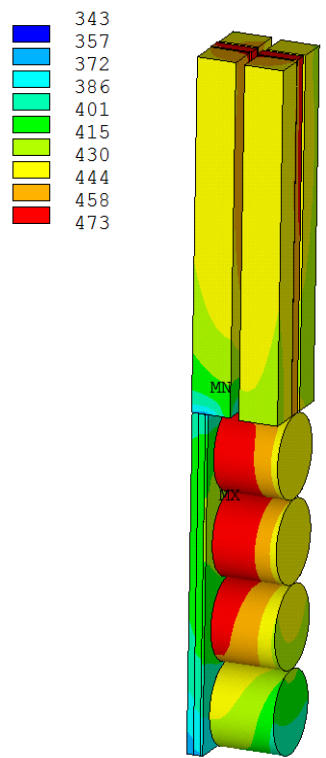

GRIC-2

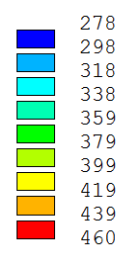

Figure 1. Results of the three-dimensional ANSYS heat transfer calculation of graphite specimens, for the two rabbit configurations with a $450^{\circ} \mathrm{C}$ target specimen temperature.

The final specimen temperature for each rabbit was determined from the passive silicon carbide (SiC) temperature monitors that were included in each rabbit. The irradiation temperature of the $\mathrm{SiC}$ was determined from post-irradiation annealing of the damage [25]. After the $\mathrm{SiC}$ temperature was determined, a ratio was used to determine the volume-averaged specimen temperature from the $\mathrm{SiC}$ temperature in the 3D thermal models, actual $\mathrm{SiC}$ temperature, and predicted specimen temperature. The setup in the rabbits resulted in a temperature difference of $50^{\circ} \mathrm{C}$ between the hottest and coldest specimens (volume averaged temperature for the specimen) in a single rabbit. The individual specimen temperature spread was largest for the round specimens that had less contact with the specimen holder, which reduced heat loss and thereby caused the round specimens to have a higher temperature than the bar specimens. The plot shown in Figure 2 shows the average specimen temperature for each individual rabbit. These points are divided according to design temperature, since all the rabbits at one design temperature had the same starting configuration (gas gap width and fill gas). 


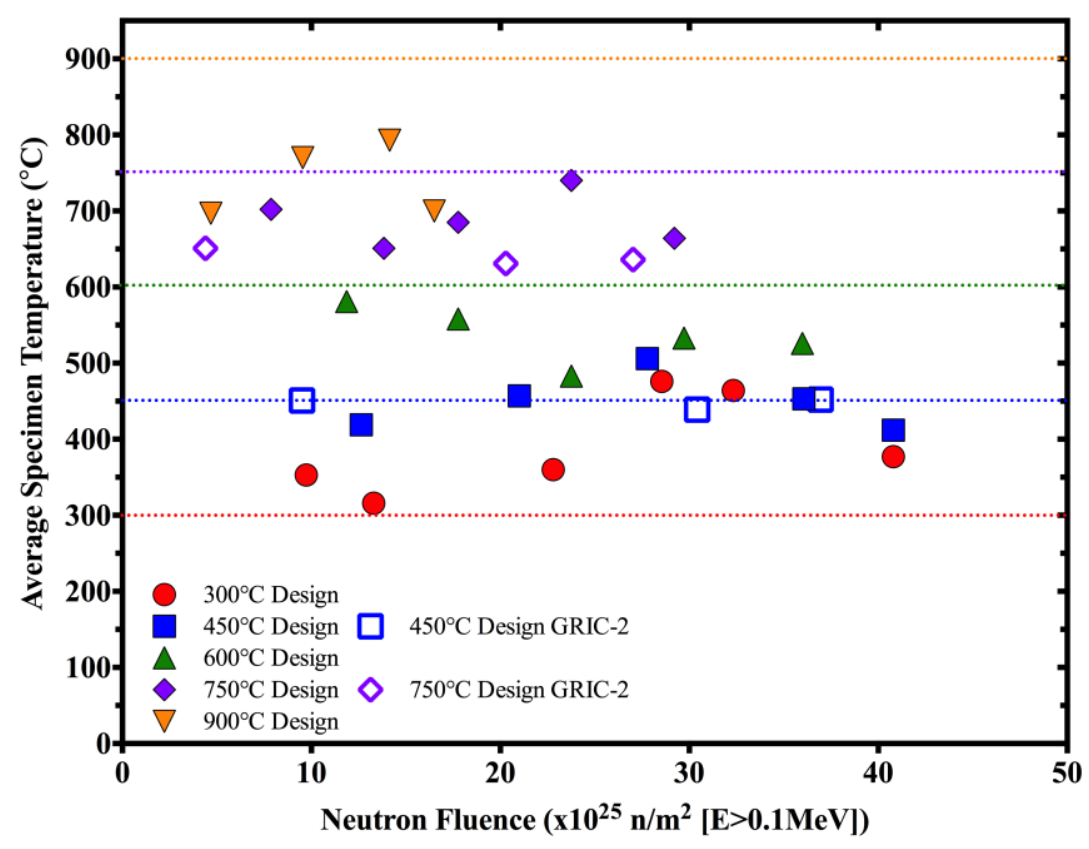

Figure 2. Irradiation envelope, showing average specimen temperature for individual rabbits at the corresponding neutron fluence.

\section{RESULTS \& DISCUSSION}

\subsection{IRRADIATION-INDUCED CHANGES}

Specimens were grouped according to the rabbit design temperature for the analysis of the irradiationinduced property changes. This decision arose from the fact that the rabbits of a specific target temperature all had the same pre-irradiation design. Therefore, it is assumed that rabbits of the same design temperature have a similar temperature history. For example, the $300^{\circ} \mathrm{C}$ rabbit at $41 \times 10^{25} \mathrm{n} / \mathrm{m}^{2}$ $[\mathrm{E}>0.1 \mathrm{MeV}])$ in Figure 2 has a final average specimen temperature of $\sim 390^{\circ} \mathrm{C}$, but if this rabbit had been removed at $29 \times 10^{25} \mathrm{n} / \mathrm{m}^{2}[\mathrm{E}>0.1 \mathrm{MeV}]$ ) then the average specimen temperature would have been around $490^{\circ} \mathrm{C}$. The temperature ranges reported throughout the rest of this paper are essentially the timeaveraged temperature of a set of rabbits. The irradiation temperature of the specimens, calculated after removal from HFIR, was used to determine the average and one standard deviation of the temperature for a given set of rabbits. Table 4 provides a summary of the design and actual specimen temperatures, and the neutron fluences for each temperature range. As mentioned in Section 2.3, the largest difference between the average specimen temperature within a single rabbit was $\sim 50^{\circ} \mathrm{C}$, but the large spread in the temperature range for each group of rabbits is due to the changes to the rabbit average specimen temperature from the irradiation history. Each temperature and fluence combination in Table 4 refers to a single rabbit, with a total of 31 rabbits undergoing irradiation. All rabbits were irradiated for a varied number of cycles to obtain the desired fluence, but all irradiation occurred between HFIR cycle 434 and 452. The fluence measurement units in this work are $\mathrm{n} / \mathrm{m}^{2}[\mathrm{E}>0.1 \mathrm{MeV}]$, which is converted to displacements per atom (dpa) by multiplying by a factor of $0.73 \times 10^{-25} \mathrm{dpa}$ per $\mathrm{n} / \mathrm{m}^{2}$ [E>0.1MeV] [26]. It is quite apparent that the high temperature rabbits did not reach the design temperature, because at 
temperatures above $600^{\circ} \mathrm{C}$ there is significant axial heat loss, even with the inclusion of insulating materials at the top and bottom of the rabbits which was not captured in the two-dimensional heat transfer calculations.

Table 4. Summary of irradiation conditions (design and actual) and approximate turn-around fluence for each temperature set.

\begin{tabular}{|c|c|c|c|}
\hline $\begin{array}{c}\text { Rabbit Design } \\
\text { Temperature } \\
\left({ }^{\circ} \mathrm{C}\right) \\
\end{array}$ & 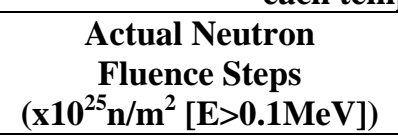 & $\begin{array}{c}\text { Actual } \\
\text { Temperature } \\
\text { Ranges }\left({ }^{\circ} \mathrm{C}\right) \\
\end{array}$ & $\begin{array}{c}\text { Turn-Around Fluence } \\
\text { from Parabolic Fit } \\
\left(\mathbf{x 1 0}^{25} \mathbf{n} / \mathbf{m}^{2}[\mathrm{E}>0.1 \mathrm{MeV}]\right)\end{array}$ \\
\hline 300 & $10,13,23,2932,41$ & $395^{\circ} \mathrm{C} \pm 62^{\circ} \mathrm{C}$ & $18(\sim 13 \mathrm{dpa})$ \\
\hline 450 & $9,13,21,28,30,36,37,41$ & $459^{\circ} \mathrm{C} \pm 37^{\circ} \mathrm{C}$ & $15(\sim 11.3 \mathrm{dpa})$ \\
\hline 600 & $12,18,24,30,36$ & $535^{\circ} \mathrm{C} \pm 33^{\circ} \mathrm{C}$ & $14(\sim 10 \mathrm{dpa})$ \\
\hline 750 & $4,8,14,18,20,24,27,29$ & $684^{\circ} \mathrm{C} \pm 41^{\circ} \mathrm{C}$ & 10 ( 7.6 dpa) \\
\hline 900 & $5,10,14,17$ & $738^{\circ} \mathrm{C} \pm 43^{\circ} \mathrm{C}$ & $10(\sim 7.6 \mathrm{dpa})$ \\
\hline
\end{tabular}

\subsubsection{Dimension and Volume}

The nominal changes to the specimen dimensions and volume are plotted versus fast neutron fluence in Figure 3 and Figure 4. In both figures the trend lines were fit with a parabolic function as an empirical fit to highlight the behavioral trends. The behaviors observed for these changes are two-fold: expected volumetric changes and unexpected dimensional anisotropy. The volume is observed to decrease for low fluence, reach a minimum volume, and then begin swelling. The densification is more severe and takes longer to cease at lower irradiation temperatures. This is the same behavior that has been observed for many medium- and large-grain graphite grades that were irradiated at multiple temperatures $[3,5-9,12$, 16]. All these changes are thought to be a result of the pre-existing Mrozowski cracks and the anisotropic grain growth (swelling in c-direction and shrinkage in a-direction). During the low-fleunce regime the observed densification occurs because c-direction growth is filling in the pre-existing Mrozowski cracks, so the shrinkage in the a-direction is the dominant change to the macroscopic volume. In the mediumfluence regime the Mrozowski cracks are being filled in and the c-direction growth begins to surpass the a-axis contraction, and causes the formation of new cracks between grains. This causes the turn-around behavior where densification ceases and swelling begins. The high-fluence behavior is dominated by the c-direction growth that causes internal stresses that result in new cracks and porosity. The temperature dependence of the turn-around fluence is because at lower temperatures there is more Mrozowski crack volume available since the thermal expansion of the grains fills less of the cracks. The approximate turnaround fluences are listed in Table 4 and are plotted versus average specimen temperature in Figure 5. The turn-around fluence shows an Arrhenius dependence on specimen temperature (solid line in Figure 5) for this range, while a linear fit provides a similar result (dashed line in Figure 5). 


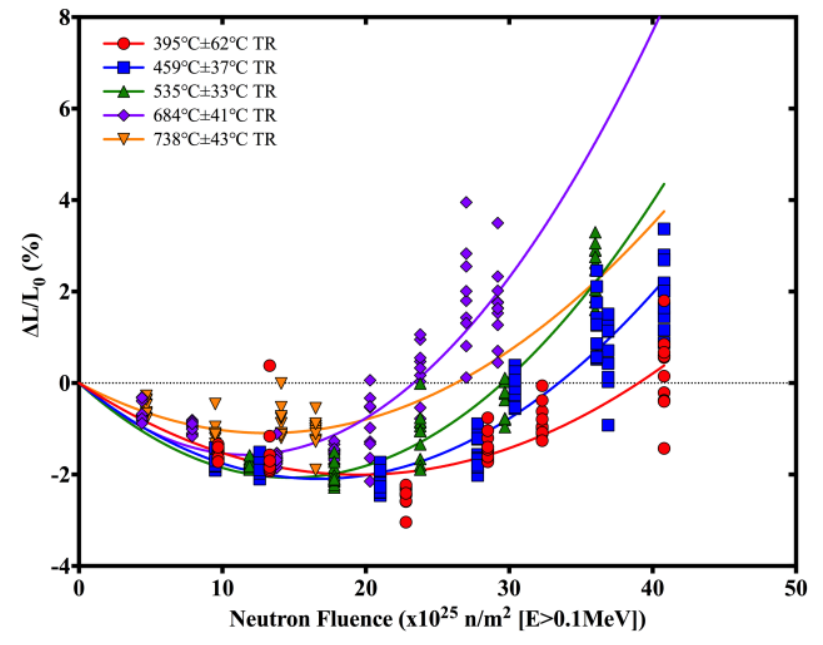

(a)

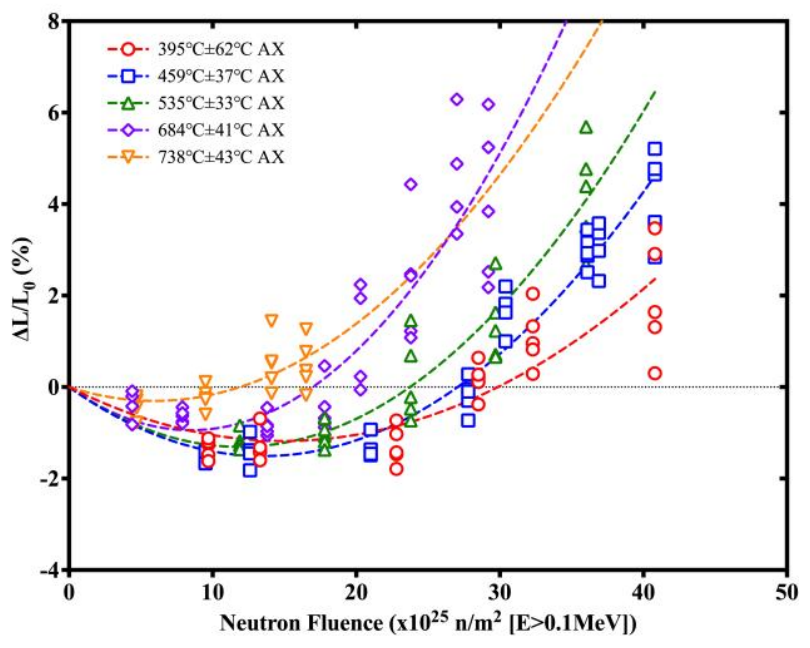

(b)

Figure 3. Measured change of specimen dimensions, as a function of fluence, for different irradiation temperatures, in the (a) transverse and (b) axial directions. Data points signify individual measurements. The lines were fitted to the data using a second-order polynomial.

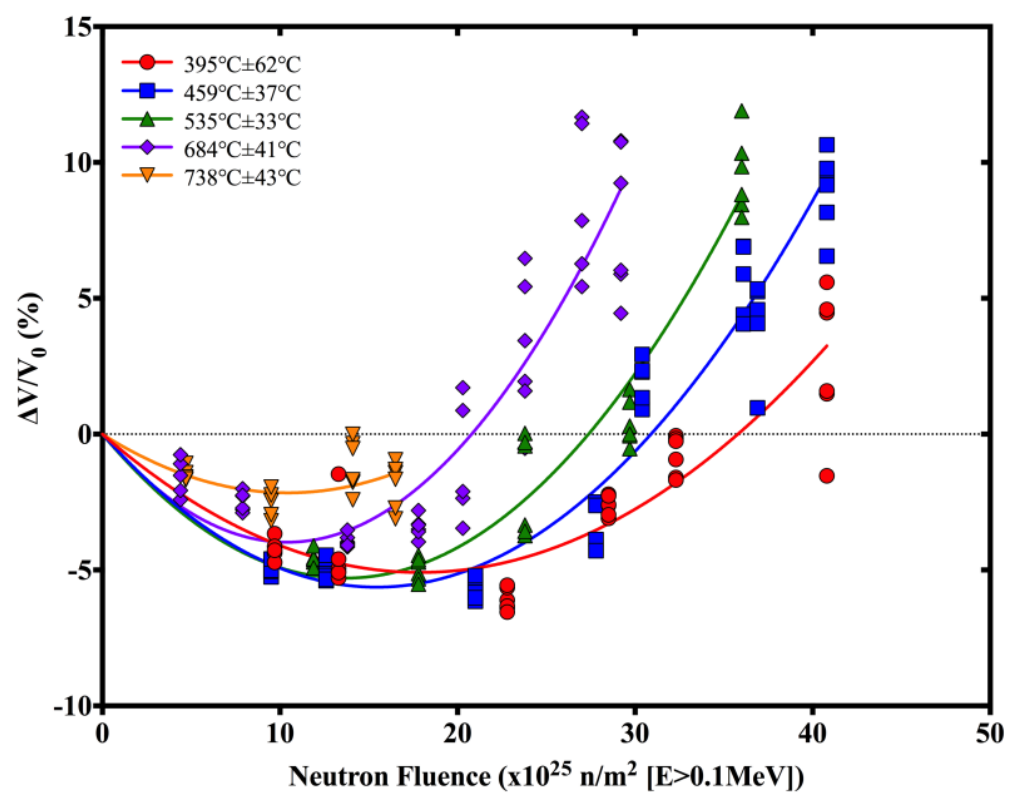

Figure 4. Specimen volume change versus neutron fluence for specimens irradiated at different temperatures. Each data point is the volume change of an individual specimen. The lines were fitted to the data using a second-order polynomial. 


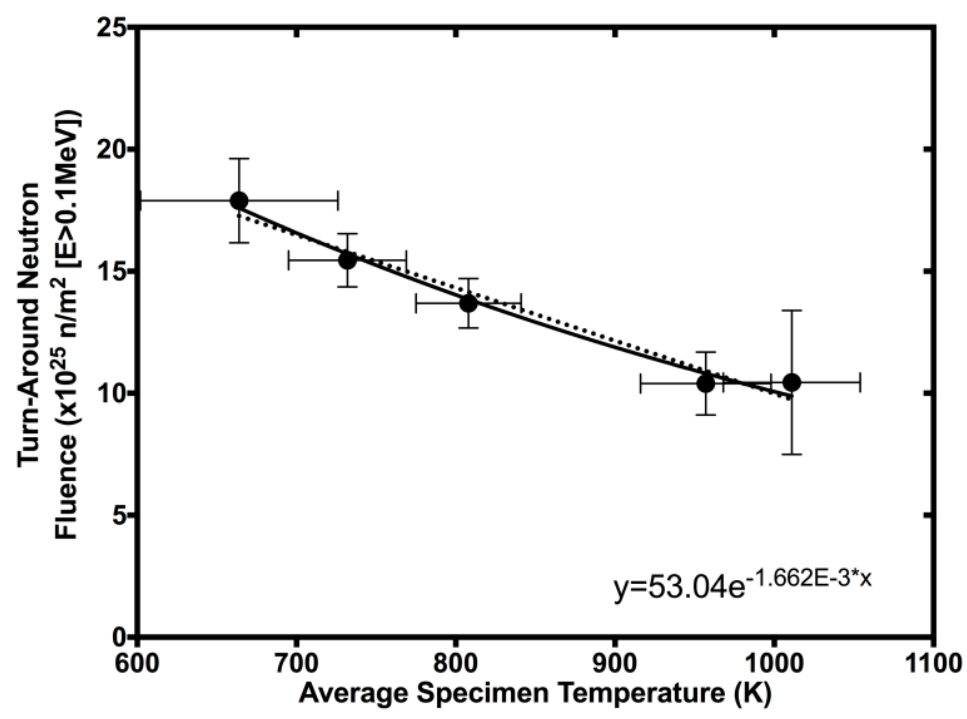

Figure 5. Plot of turn-around fluence versus average specimen temperature. Solid line is the Arrhenius fit of the data, while the dashed line is a linear fit.

The second finding, which was unexpected, was the significant anisotropy in the dimensional change. Very little work has studied the differences in the anisotropic length-change behavior of isostatically molded graphites [27]. G347A has a CTE anisotropy factor of 1.07 that falls within the anisotropy ratio necessary to be considered isotropic [28], which is determined from the ratio of the mean CTE at $500^{\circ} \mathrm{C}$ for the two different orthogonal directions. These results have shown that the dimensional change anisotropy is significantly larger than the CTE anisotropy. The ratio of the fluences for the directions to return to pre-irradiation length can be used as a measure of the dimensional change anisotropy. For example, the specimens irradiated at $395^{\circ} \mathrm{C} \pm 62^{\circ} \mathrm{C}$ returned to initial length in the axial direction around a fluence of $\sim 30 \times 10^{25} \mathrm{n} / \mathrm{m}^{2}[\mathrm{E}>0.1 \mathrm{MeV}](\sim 22 \mathrm{dpa})$, while the transverse direction required a $\sim 30 \%$ higher fluence to return to initial length. All the temperatures had a dimensional change anisotropy around 1.3, which is much larger than expected and is similar to trends observed in medium- and coarse-grained graphite $[9,12,13]$. It is interesting to point out that the Axial direction of the CTE was the larger value by $\sim 7 \%$, and that the axial direction returned to pre-irradiation dimensions at a rate that was $\sim 30 \%$ faster than the transverse directions. The higher CTE in this direction suggests that there are more grains with c-axis aligned parallel to the axial direction and/or less accommodation porosity. This means that more of accommodation porosity (Mrozowski cracks) are filled in by thermal expansion, so there is less accommodation available to allow for dimensional change of the grains. This may account for some of the dimensional change anisotropy, but it does not account for all of it. The second possibility is that there is a second type of accommodation porosity (besides the Mrozowski cracks) that is preferentially orientated in the transverse directions. This porosity would allow for more expansion of grains orientated with their c-axis in the transverse directions, thereby making the fluence to return to pre-irradiation larger.

The measured dimensional and volume changes for the G458A specimens are plotted with the G347A results from the same temperatures in Figure 6. It is interesting to observe that the dimensional change of the G458A is more anisotropic than G347A (Figure 6a), where the fluence to return to initial length in the TR direction is a factor of 2.1 larger than the AX direction for G458A, whereas G347A the TR direction 
was only a factor of 1.3 larger. This may be a result of the CTE-based anisotropy being larger for G458A (was not measured), a difference because of the different filler material, or differences in the graphitization (temperatures are unknown). Both grades had a similar starting density, so the similarities in the volumetric contraction and turn-around fluence were expected.

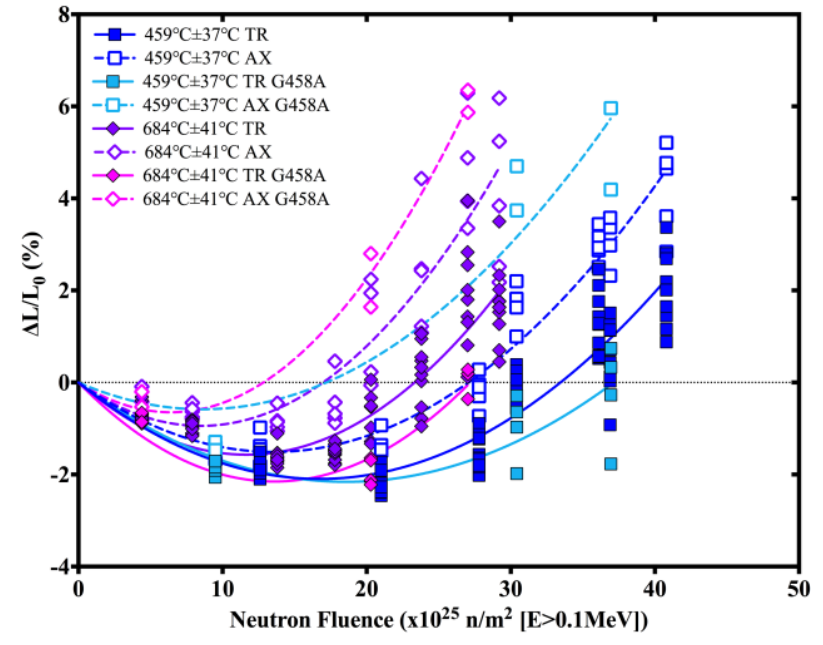

(a)

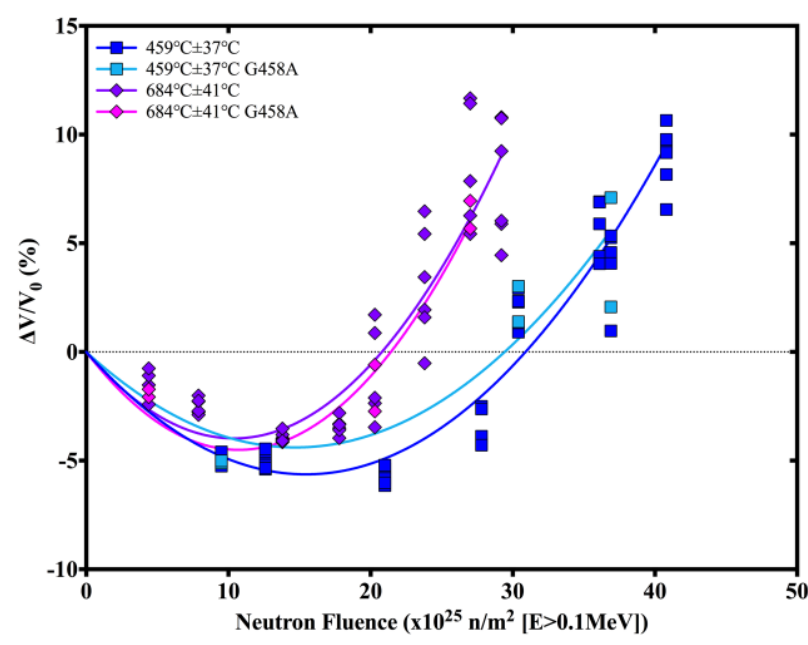

(b)

Figure 6. Changes to (a) dimension and (b) volume of G458A and G347A irradiated at similar temperatures.

\subsubsection{Elastic Properties}

The nominal changes to measured Young's and shear moduli are plotted in Figure 7a-b. The same parabolic curve fit was used, since it has been shown for oxidized graphite [29] that Young's modulus changes are primarily controlled by changes to the density. The pre-irradiation anisotropy of the Young's modulus was $\sim 1.04$ (11.13 GPa for axial versus $10.72 \mathrm{GPa}$ for transverse). The change to the Young's modulus was relatively constant for the specimens that were low fluence, but for the specimens past turnaround the difference between the orientations became more pronounced. The shear modulus followed similar trends as the Young's modulus. The average pre-irradiation Poisson's ratio calculated from the two measurements was 0.25 . After irradiation the average Poisson's ratio slightly increased to 0.29 , but ranged from 0.22 to 0.35 and did not display any effects caused by irradiation temperature. The comparison between the Young's modulus changes for the two grades are plotted in Figure 7c. The net change of G458A was lower than G347A at both temperatures. This difference is not explained by a significant difference in the specimen volume change or that the pre-irradiation Young's modulus of G458A was 5\% higher than G347A. This suggests that a difference in the filler, or microstructure, is the source of this difference. 


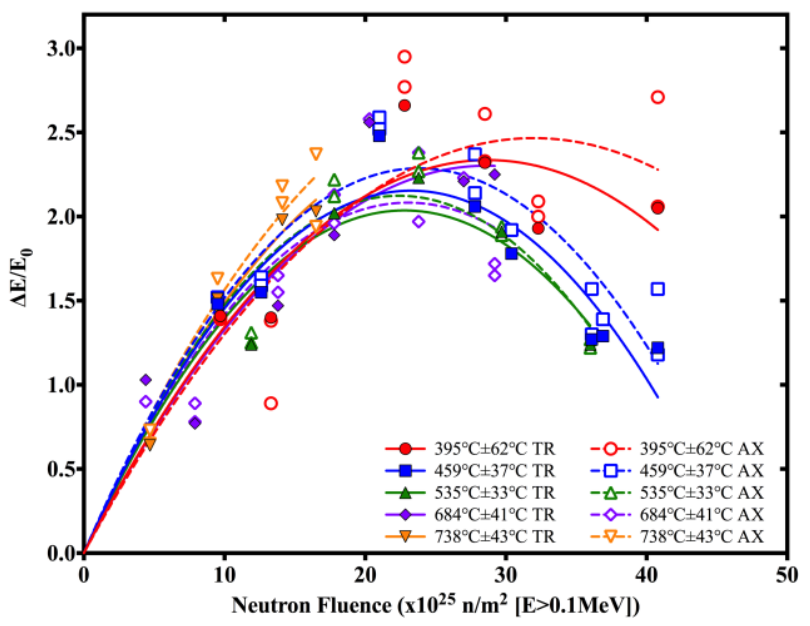

(a)

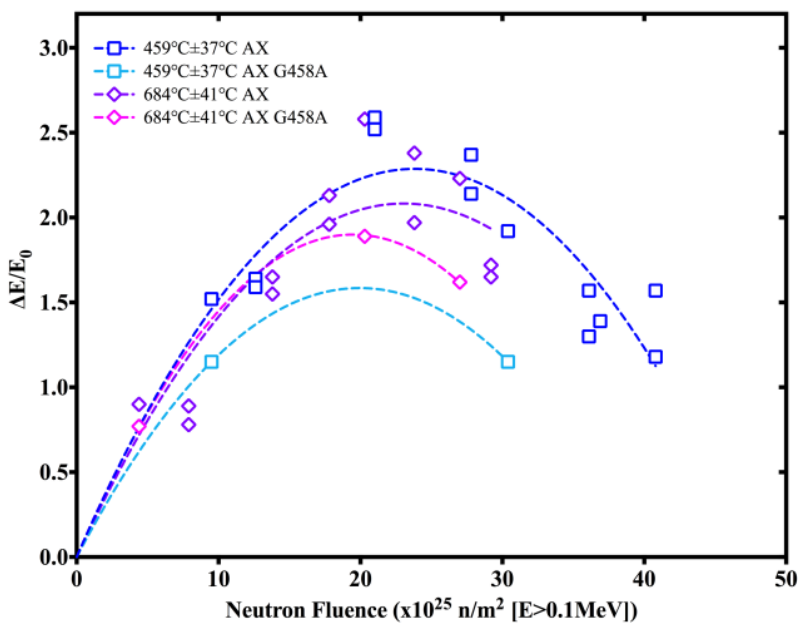

(c)

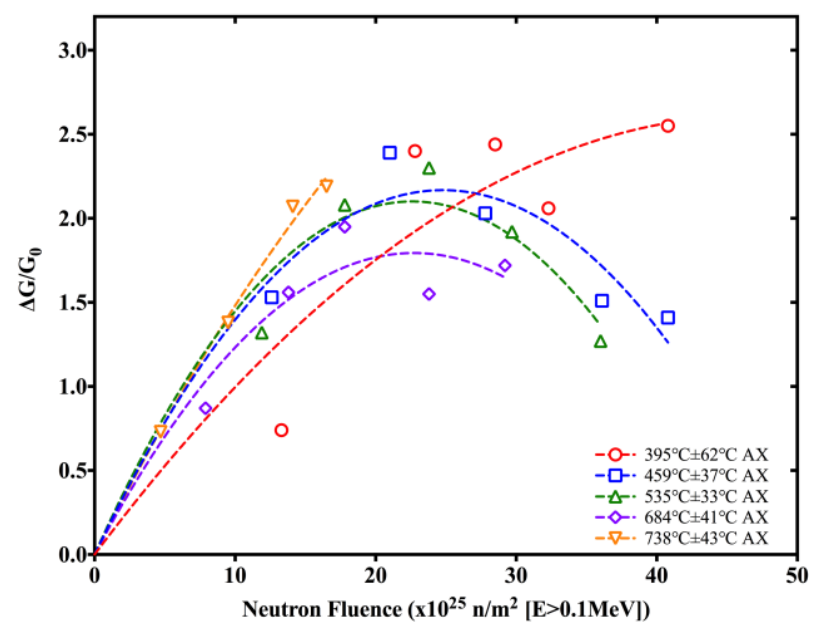

(b)

Figure 7. Normalized change of dynamic (a) Young's modulus and (b) shear modulus as a function of temperature and fluence. (c) Change of Young's modulus of G347A and G458A irradiated at the same temperatures. Each data point in the graph is a single measurement. The lines were fitted to the data using a second-order polynomial.

In older work, the Young's modulus was observed to undergo a rapid rise with low fluence, followed by a short plateau, then following a parabolic shape that is similar to the density changes $[1,3,6,7,9,12,13$, 15]. The early rise has been attributed to pinning of dislocations in the grains, while the later change is controlled by the porosity loss and creation. It is unlikely that this same pinning mechanism would cause significant changes in the results in this work, due to this graphite having a much smaller grain size. In this case it is plausible that fine-grained graphite does not undergo the low-fluence increase of Young's modulus due to dislocation pinning, since the total length a dislocation can bow is much smaller, and instead the changes to Young's modulus are only driven by changes to the microstructure. This conjecture requires low-fluence results for this or other fine-grained graphites to determine whether the low-fluence behavior would be the same are coarser-grained grades. Limited work has studied the effect of irradiation on the Poisson's ratio [30]. The results observed little-to-no change to the Poisson's ratio, which suggests 
that the shear modulus displayed similar behavior as the Young's modulus. This similarity of the Young's and shear changes was also observed in this work.

\subsubsection{Electrical Resistivity}

The change of the room-temperature electrical resistivity versus fast neutron fluence is plotted in Figure 8. The sudden increase in resistivity followed by a long plateau is similar to trends observed in mediumand coarse-grained graphite $[1,3,7,12]$. The rapid increase has been attributed to distortion within the crystals that shortens the electron mean free path, while the plateau is attributed to the increasing electron hole and scattering site concentrations negating any further changes [12]. The multiple temperature ranges in this work provide some insight, which has only had limited observation in previous work. The first is the fact that the net increase of the resistivity at the low and intermediate fluences is nearly constant, around a factor of 1.5 , for all the temperatures investigated. This was also observed by Haag [12], but the ATR-2E showed an increase by a factor of $\sim 2$. Additionally, there is a rapid increase in the resistivity when the sample surpasses the pre-irradiation volume and moves into the positive swelling regime. The work on ATR-2E [12] showed a similar behavior, except that the increase appeared to begin shortly after turn-around rather than after positive swelling. This high-fluence related increase is not surprising since the electron pathways should become more distorted as the crystal structure is lost during swelling.

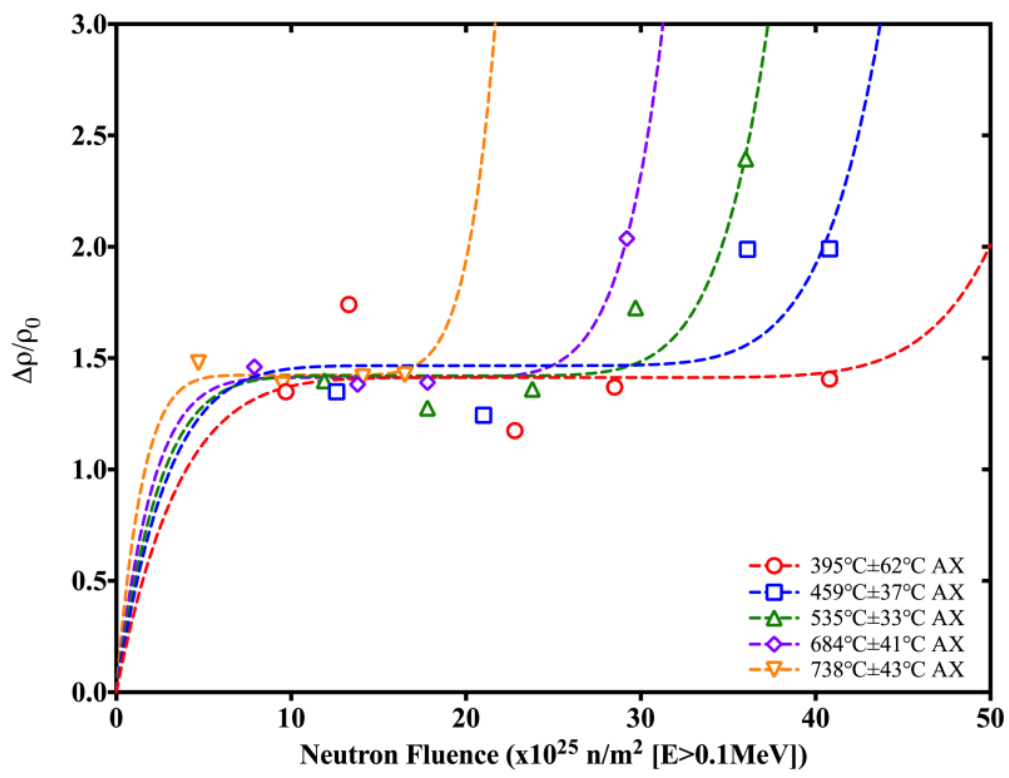

Figure 8. Normalized change of electrical resistivity of specimens, with axial orientation, versus neutron fluence. Each data point in the graph is a single measurement.

\subsubsection{Equibiaxial Strength}

The effect of neutron fluence on the average equibiaxial strength change is plotted in Figure 9a, error bars are $\pm 1 \sigma$. For each condition 8-10 specimens were tested, and the errors bars include the standard 
deviation of the irradiated specimens and propagation of the standard deviation of the pre-irradiation strength. Similar strength change behaviors have been observed in many other graphite irradiation programs $[1,6,7,9,12,13,15]$. In previous work the strength change was shown to increase as a function of the Young's modulus increase to the one half power [7]. The change of strength is plotted versus the measure Young's modulus change in Figure 9b, to see whether this half power dependence is accurate for these results. In figure Figure 9b, the connecting lines trace the pathway of increasing neutron fluence. Even before turn-around the behavior appears to have a power dependence on Young's modulus change of 0.3-0.8, but after turn-around the behavior is markedly different. As with the Young's modulus change, there is not sufficient low-fluence data in this work to discuss whether the rapid rise observed for larger-grained graphites does or does not occur in this fine-grained grade.

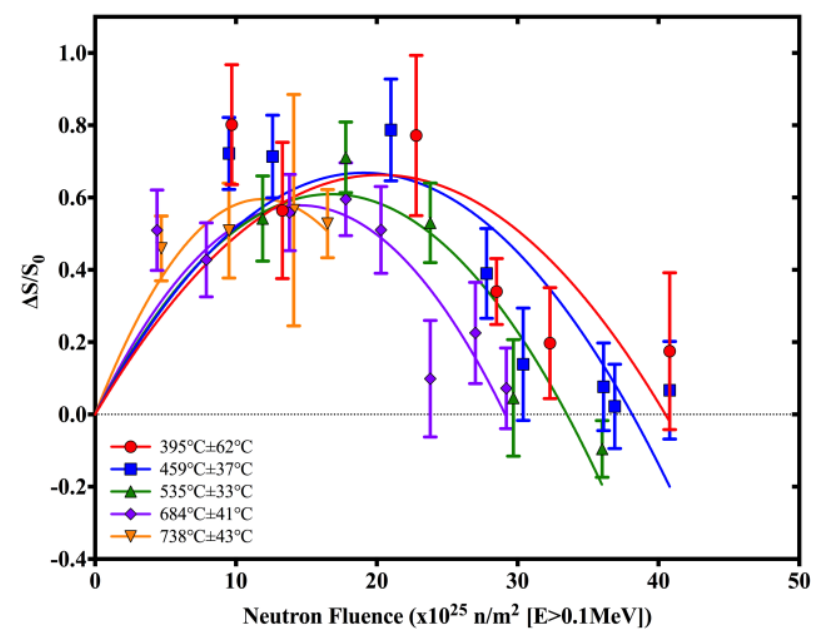

(a)

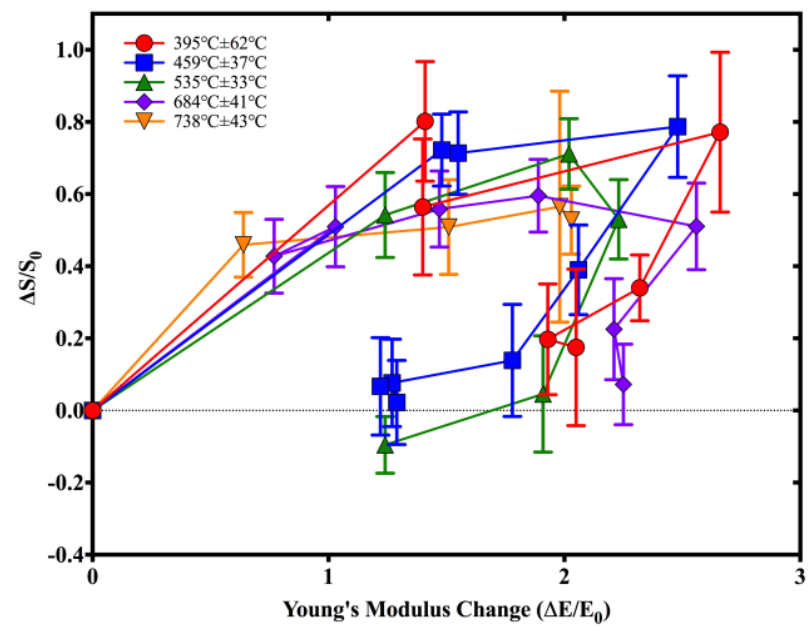

(b)

Figure 9. Change of average equibiaxial strength versus (a) neutron fluence and (b) Young's modulus change (error bars are $\pm 1 \sigma$ ). The lines in (a) were fitted to the data using a second-order polynomial, while lines in (b) are only to show the increasing neutron fluence.

\subsubsection{Thermal Conductivity}

Thermal conductivity was measured both at $50^{\circ} \mathrm{C}$ and at the irradiation temperature. The thermal conductivity of the pre-irradiation specimens and specimens irradiated at $459^{\circ} \mathrm{C} \pm 37^{\circ} \mathrm{C}$ are plotted versus measurement temperature in Figure 10 (irradiation temperature indicated with vertical dashed line). 


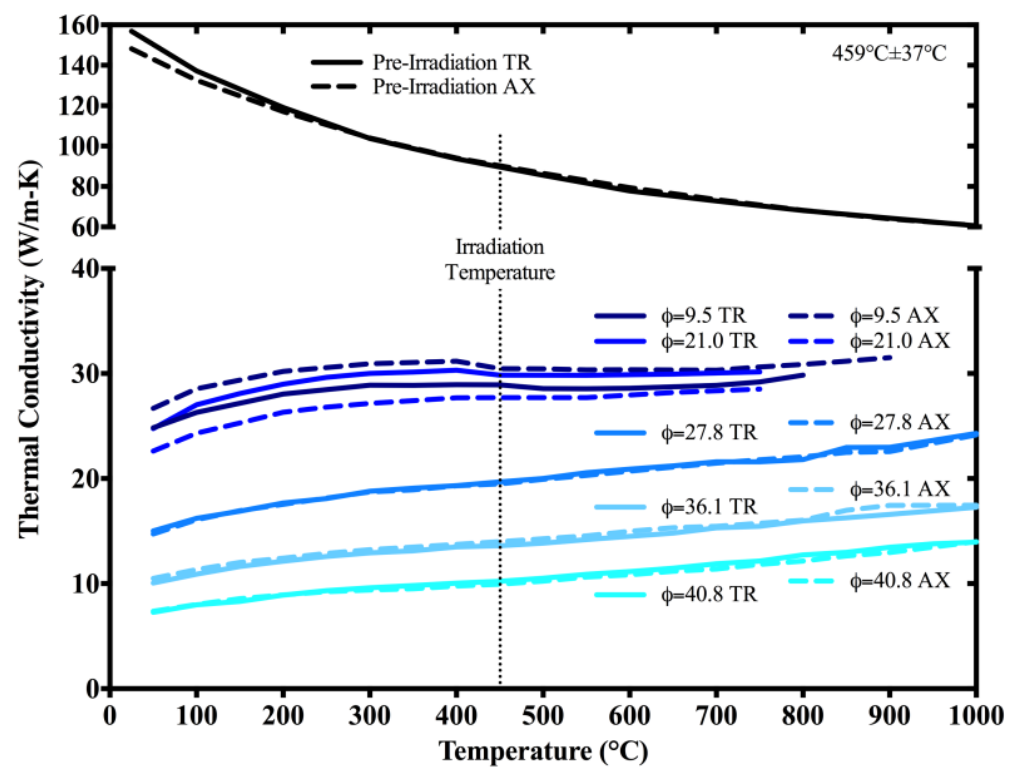

Figure 10. Plot of measured thermal conductivity versus measurement temperature for as-received and specimens irradiated at $459^{\circ} \mathrm{C} \pm 37^{\circ} \mathrm{C}$. The vertical dashed line indicates the irradiation temperature. The labels indicate the specimen orientation and total neutron fluence $\left(x 10^{25} \mathrm{n} / \mathrm{m}^{2}[\mathrm{E}>0.1 \mathrm{MeV}]\right)$.

\subsubsection{Room Temperature}

The reduction of the thermal conductivity, measured at $50^{\circ} \mathrm{C}$ is plotted in Figure 11a (pre-irradiation conductivity was TR-138 W/m/K and AX-148 W/m/K). The ease of measurement of the room temperature thermal conductivity, resulted in the majority of the historical work only studying the effects of irradiation on the room temperature thermal conductivity (measured at temperatures of $25-40^{\circ} \mathrm{C}$ ) $[1,3$, $6,7,12]$. In most cases the change in the fractional resistance was reported, where it is calculated according to:

$$
\text { Equation 1: } \frac{K_{0}}{K_{i r r}}-1
$$

where $K_{i r r}$ is irradiated thermal conductivity and $K_{0}$ is the pre-irradiation value. The increase of the resistance in the literature had a plateau value ranging from 2-80, with the results for irradiation temperatures above $300^{\circ} \mathrm{C}$ ranged from $2.5-5$ [1, 3, 6, 7, 12]. Haag [12] discussed that the thermal resistance should plateau at an elevated value followed by a second increase that begins at turn-around, called "secondary breakdown". This behavior occurs because the in-crystal changes to the structure control the low-fluence increase, while the secondary breakdown is due to the pore generation. The thermal resistivity of the material in this work is plotted versus neutron fluence in Figure 11b. The thermal resistance behavior does not appear to be similar to trends observed in the literature. There does not appear to be a plateau and instead there is the rapid increase followed by a slower but continuous increase. 


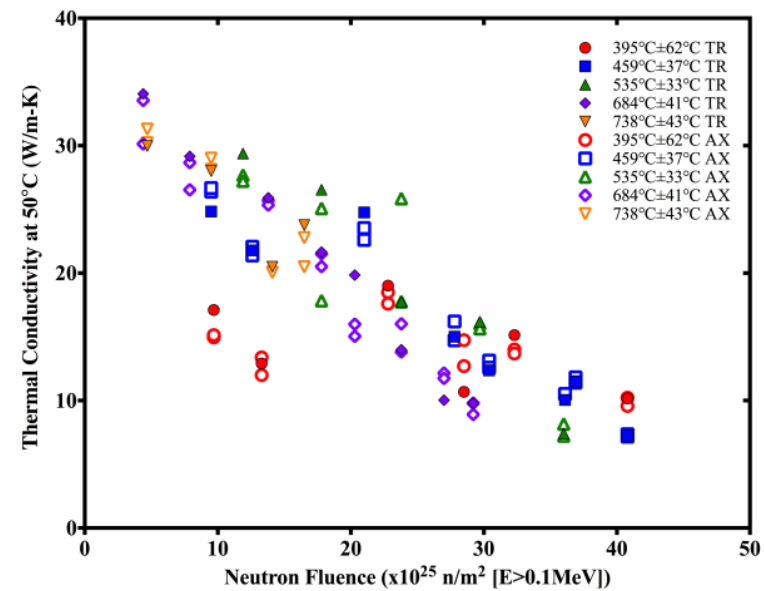

(a)

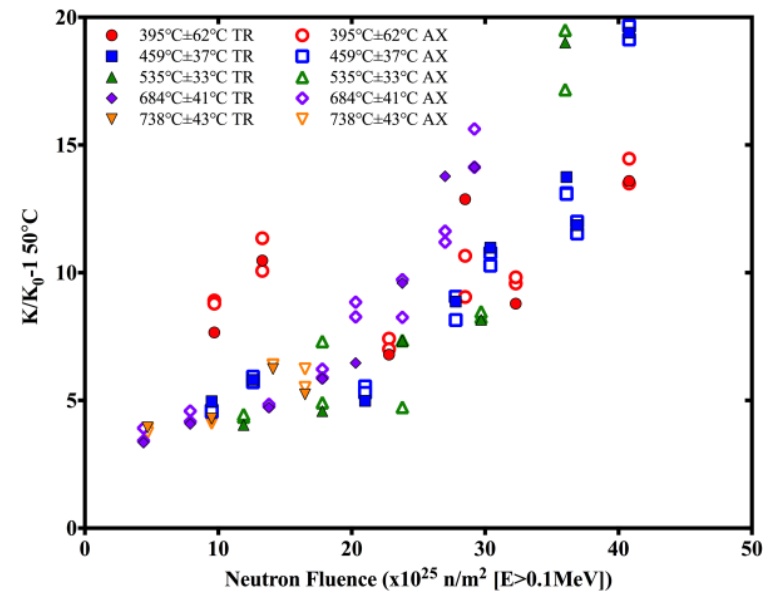

(b)

Figure 11. Plot of post-irradiation (a) thermal conductivity and (b) thermal resistance, both measured at $50^{\circ} \mathbf{C}$.

\subsubsection{Irradiation Temperature}

There has only been limited historical results that investigated the changes to the thermal conductivity at the irradiation temperature (see [15] for example). All that has been observed is a similar decrease to the conductivity with increasing dose. This work included a comprehensive set of temperatures and neutron fluences, which provides more insight into the reduction at elevated temperatures. The thermal conductivity at the specimen irradiation temperature is plotted versus neutron fluence in Figure 12a, while the normalized change of thermal conductivity is plotted in Figure 12b. The comparison between G347A and G458A changes of thermal conductivity is plotted in Figure 12c. The grade comparison shows no significant differences between the behaviors of these two materials. 


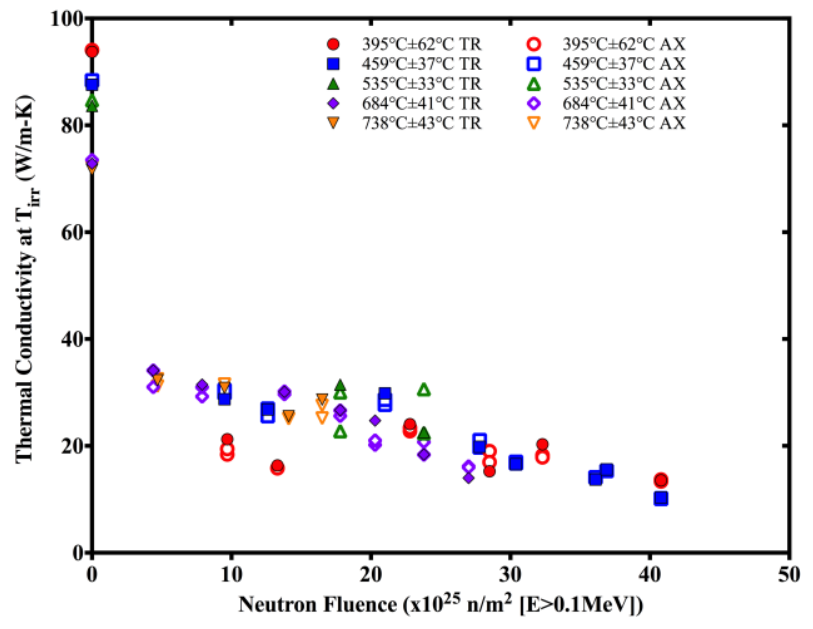

(a)

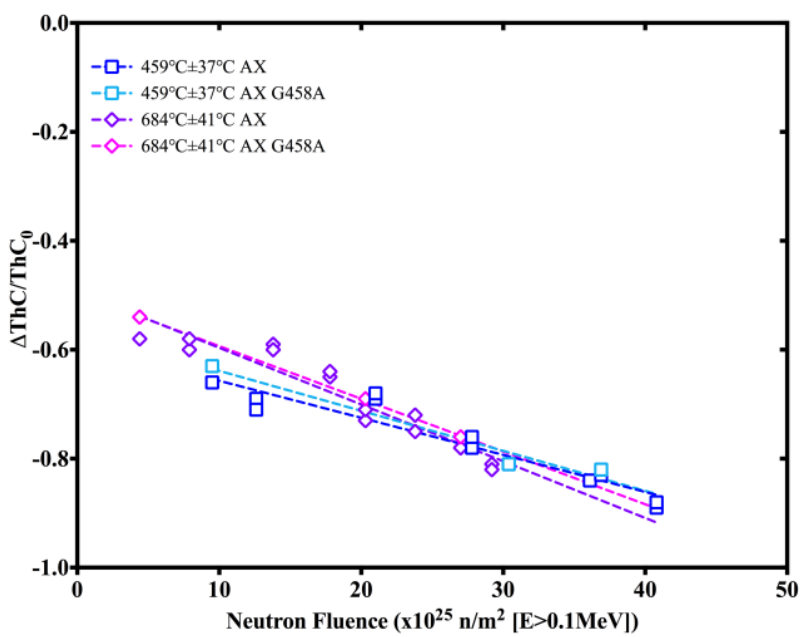

(c)

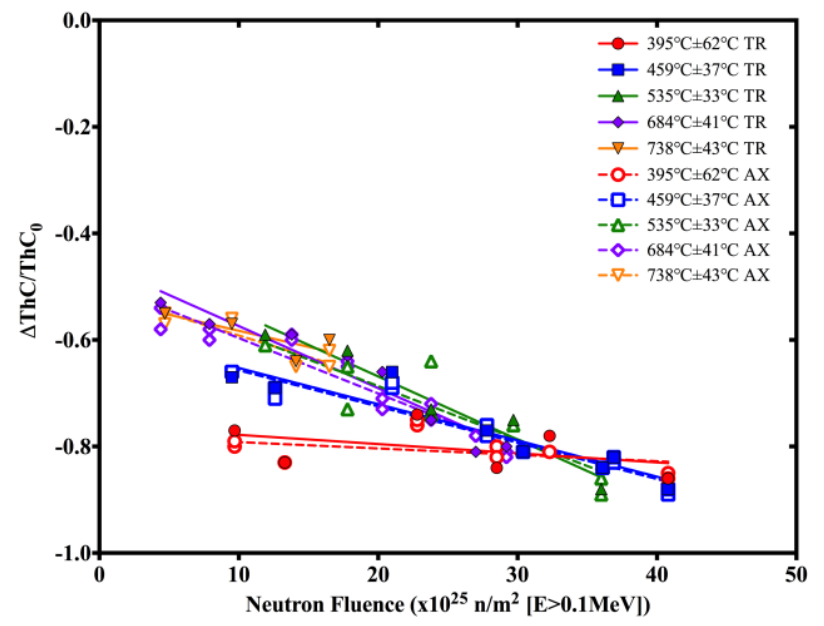

(b)

Figure 12. (a) Thermal conductivity measured at irradiation temperature (values at 0 fluence are the preirradiation values at the irradiation temperature). Thermal conductivity change normalized by preirradiation thermal conductivity of (b) G347A and (c) comparison of G347A and G458A.

An interesting trend observed in the measured thermal conductivity is that even though the pre-irradiation high temperature values range from $70-90 \mathrm{~W} / \mathrm{m} / \mathrm{K}$ the post-irradiation values are nearly equal at the same fluence, no matter the irradiation temperature. In Figure $12 \mathrm{~b}$ the differences due to the irradiation temperature are more apparent. The initial drop is more severe for the two lowest temperatures while the three high temperatures are similar. The initial thermal conductivity reduction is controlled by the concentration of radiation-produced defects (primarily vacancies in the basal planes), which increases phonon scattering. A lower irradiation temperature increases the defects concentrations due to reduced recombination rates and slower migration rates, which both result in smaller defects with a higher density. The higher density of defects increases phonon scattering and causes the more sever reduction of thermal conductivity at the lower irradiation temperatures. These are the in-crystal changes that Haag [12] discussed. The similarity of the initial decrease for the three highest temperatures is most likely a result of vacancies becoming mobile around $600^{\circ} \mathrm{C}$, which allows for vacancies to migrate and become larger 
defects with lower number density that results in reduced phonon scattering. The continued decrease, after the initial drop, is most likely a result of the pore generation, as postulated by Haag [12]. The temperature-dependence of the slopes in Figure 12b suggests that the pore generation rates are greater for higher irradiation temperatures. The trends shown in Figure 12a-b suggest that the irradiation temperature varies the ratios of in-crystal defects and pore generation, but this results in similar values of thermal conductivity at the same neutron fluence. The phonon-phonon scattering (Umklapp) is usually the dominant scattering process at higher measurement temperature, but the similarity of the thermal conductivity at the same dose for different temperatures suggests that the scattering from the defects have become the dominant scattering mode. This would also explain why the post-irradiation thermal conductivity has a limited temperature dependence as seen in Figure 10.

The thermal conductivity of graphite is primarily controlled by phonon scattering, which is also the mechanism that controls ceramic thermal conductivity. For this reason, it could warrant investigating the thermal conductivity in a way that has been used for ceramics. One was is to convert thermal conductivity into a term called the radiation defect resistivity $\left(K_{r d}\right)$ given by [31]:

$$
\text { Equation 2: } \frac{1}{K_{r d}}=\frac{1}{K_{i r r}}-\frac{1}{K_{0}},
$$

where $K_{i r r}$ is irradiated thermal conductivity and $K_{0}$ is the pre-irradiation value. The radiation defect resistivity, of each set of specimens, is plotted versus neutron fluence in Figure 13a, while the grade comparison is plotted in Figure 13b. The fit used for the trend lines is an exponential growth behavior given by:

\section{Equation 3: $Y=Y_{0} e^{k x}$,}

where $Y_{0}$ was set to $1 / K_{0}$ from Equation 2, and $k$ is the rate constant. It is interesting that this behavior agrees well with the fitting equation. The two sets of low temperature data that do not agree with the fit were specimens that were irradiated at temperatures below $300^{\circ} \mathrm{C}$ (Wigner temperature), which is the temperature necessary for Frenkel pairs recombination, so their higher resistivity is expected since more defects are present in the final microstructure. The other trend of interest is the rate constant increases with increasing irradiation temperature. This behavior suggests that the microstructural that are causing the resistivity increase are occurring faster at the higher temperatures. The question that remains is what microstructure features are driving this change: pore generation, crystallite size reduction, something else not observed, or a combination of multiple changes. The similarity of the resistivity for the two grades (Figure 13b) suggests that the sources of the increased resistivity are similar for both materials. 


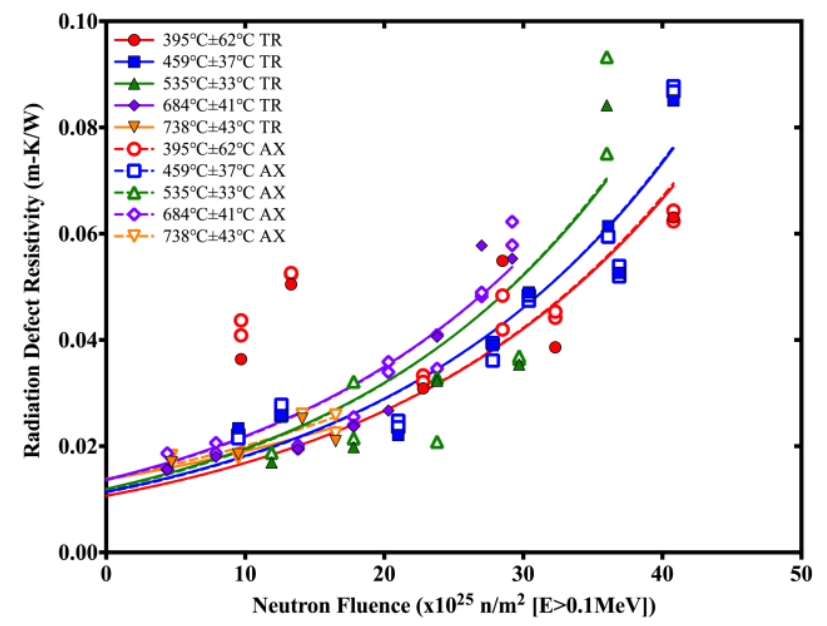

(a)

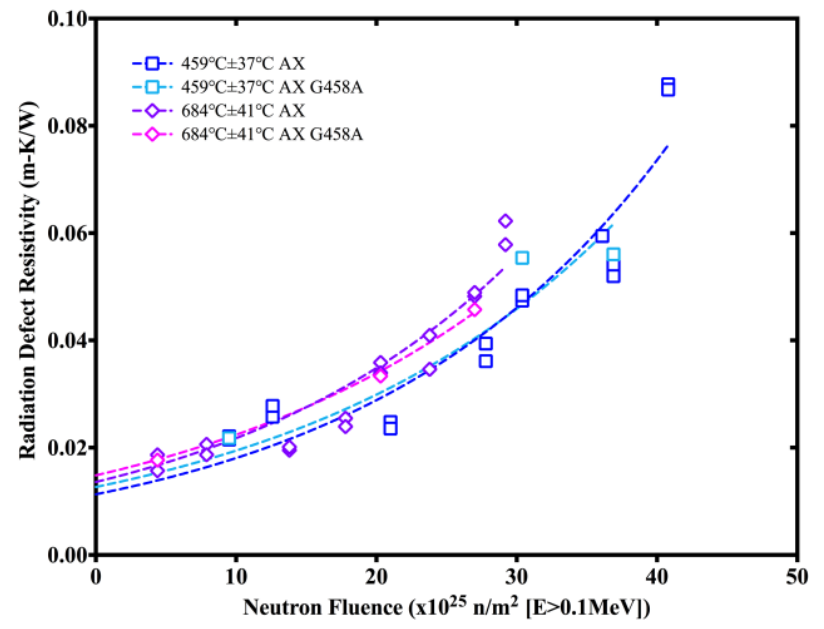

(b)

Figure 13. Changes to radiation defect resistivity.

\subsubsection{Coefficient of Thermal Expansion}

The mean CTE referenced to $25^{\circ} \mathrm{C}$ is being reported for this work. The mean CTE at a specific temperature is calculated by:

$$
\text { Equation 4: }\left[\alpha_{m}\right]_{T_{i}}=\left[\frac{\Delta L}{L_{0}} \frac{1}{\Delta T}\right],
$$

where $\alpha_{m}$ is the mean coefficient of thermal expansion, $\Delta L$ is the change in length of specimen between temperatures $T_{i}$ and $T_{0}, T_{0}$ is $25^{\circ} \mathrm{C}, L_{0}$ is the original length of specimen, and $\Delta T$ is the temperature difference between $T_{i}$ and $T_{0}$. The mean CTE is plotted versus measurement temperature in Figure 14, which includes values measured for the material before irradiation and also for multiple fluences with the same irradiation temperature (irradiation temperature indicated with vertical dashed line). 


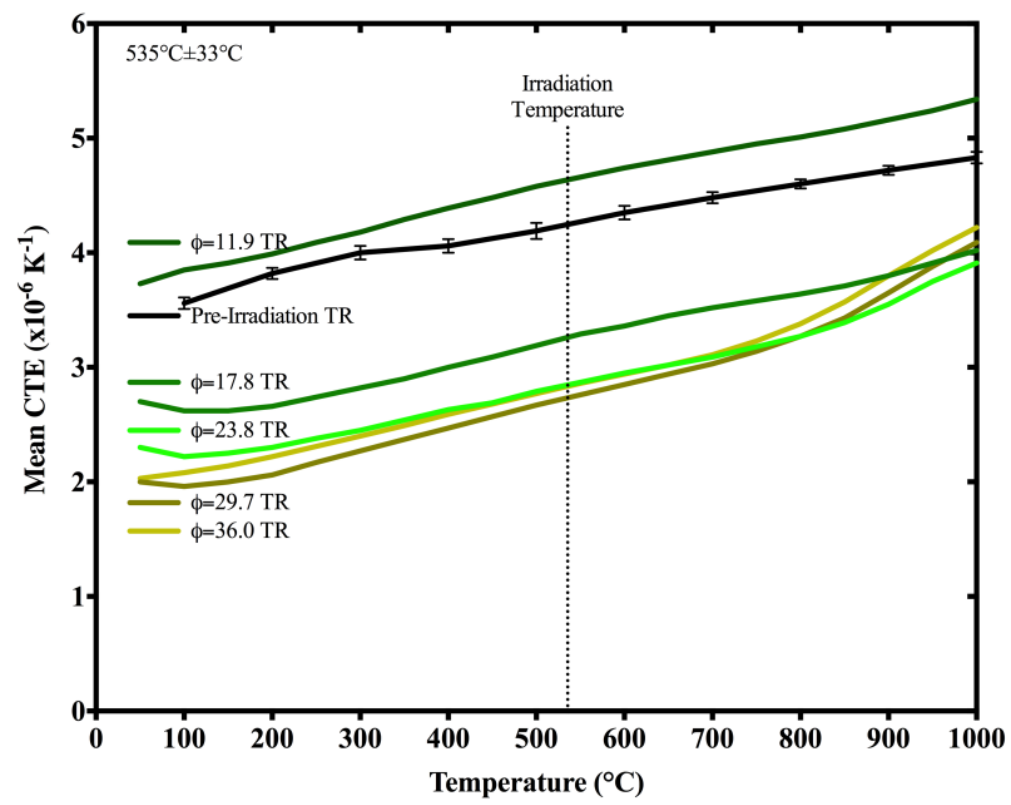

Figure 14. Plot of mean CTE (referenced to $25^{\circ} \mathrm{C}$ ) versus measurement temperature for as-received and specimens irradiated at $535^{\circ} \mathrm{C} \pm 33^{\circ} \mathrm{C}$. The vertical dashed line indicates the irradiation temperature. The labels indicate the specimen orientation and total neutron fluence $\left(x_{10}^{25} \mathrm{n} / \mathrm{m}^{2}[\mathrm{E}>0.1 \mathrm{MeV}]\right)$.

The mean CTE, at irradiation temperature, is plotted versus neutron fluence in Figure 15a, while the preirradiation normalized change is plotted in Figure 15b. The mean CTE change with increasing fluence is similar to behaviors observed in other graphite $[3,5,7,9,12]$, but again this larger population of fluence and temperature combinations provides additional insight into the changes. The behavior for all the temperatures is that the mean CTE rapidly rises to a peak value, followed by a rapid decrease to a longterm plateau value. The initial peak in the change appears to correlate with the fluence where the densification rate begins to slow, while the plateau appears to coincide with the turn-around fluence. These similar trends were also observed in the work from Haag [12]. The difference between ATR-2E [12] and this work is that the plateau relative change for ATR-2E was around a $40 \%$ decrease from initial for all temperatures between $300-600^{\circ} \mathrm{C}$ whereas these results show a temperature dependence in the net change. What is also interesting is that the plateau values, for all temperatures, show a small scatter around a similar value. Figure $15 \mathrm{c}$ shows the mean $\mathrm{CTE}$ at the various measurement temperatures for specimens with a total fluence around $30 \times 10^{25} \mathrm{n} / \mathrm{m}^{2}[\mathrm{E}>0.1 \mathrm{MeV}]$. The vertical dashed lines show the irradiation temperature, while the horizontal dashed lines highlight the mean CTE for the TR specimens at the respective irradiation temperatures. The grade comparison for the mean CTE change is shown in Figure $15 \mathrm{~d}$. 


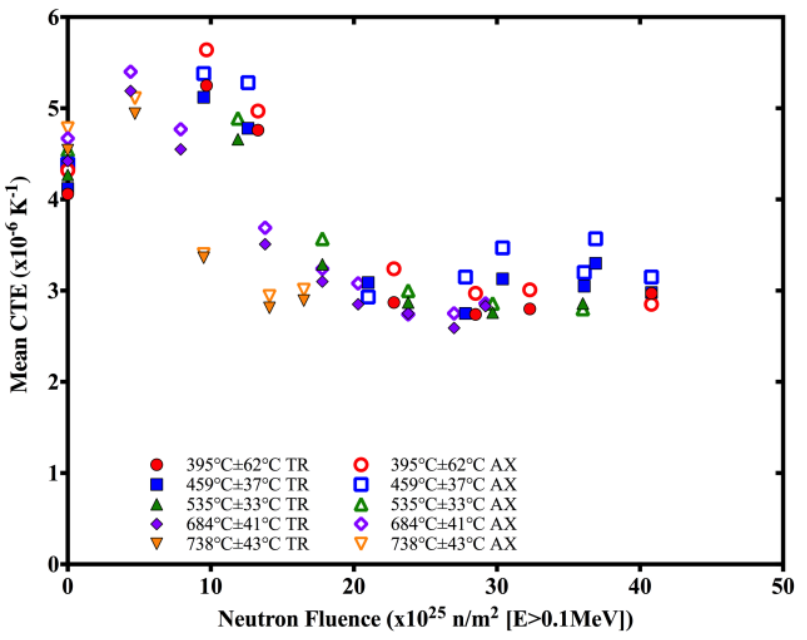

(a)

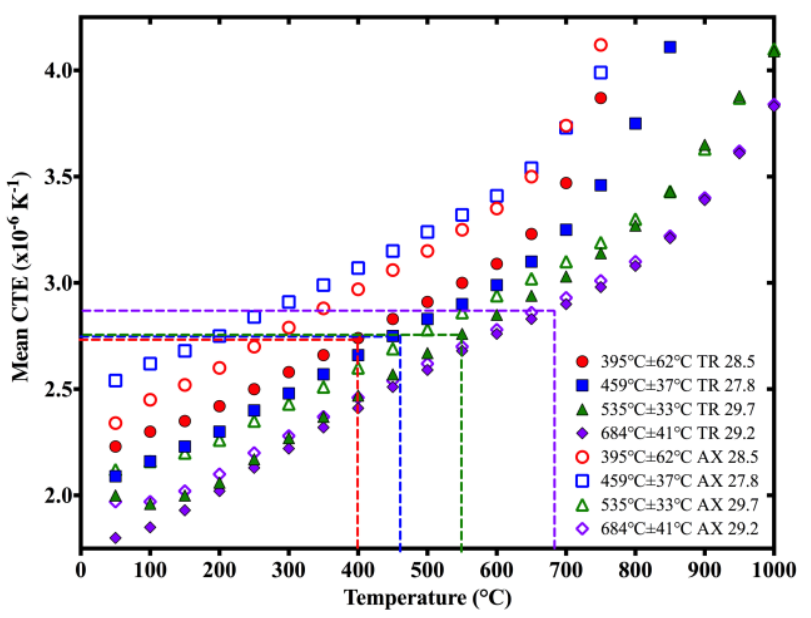

(c)

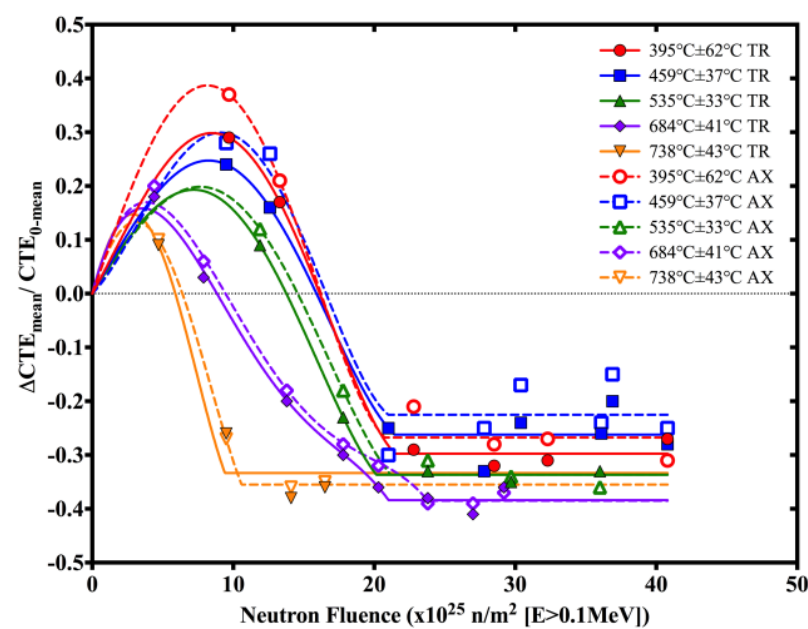

(b)

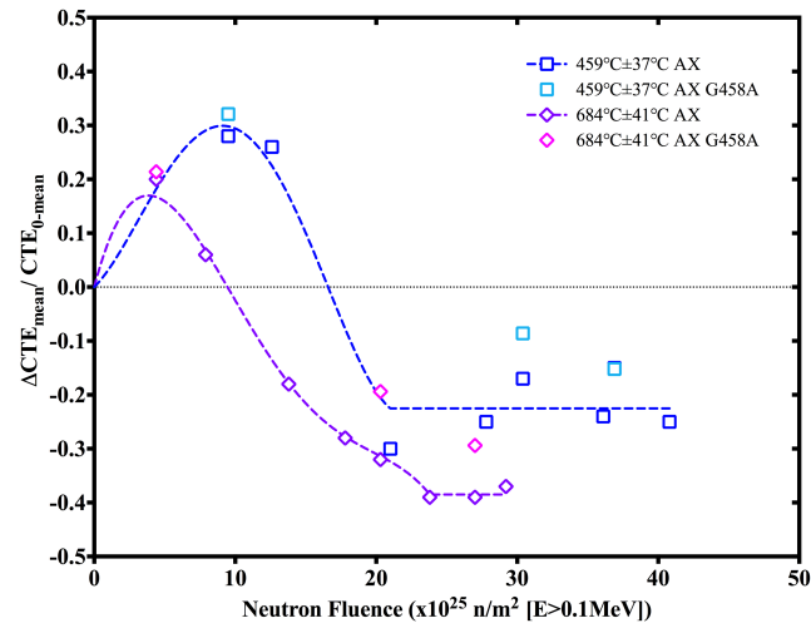

(d)

Figure 15. (a) Mean CTE, measured at irradiation temperature, versus neutron fluence. (b) Normalized change of mean CTE (referenced to $25^{\circ} \mathrm{C}$ ), measured at irradiation temperature, plotted versus neutron fluence. The low-fluence change is fitted with a second-order polynomial while the higher fluence is fitted with a constant. (c) Mean CTE plotted versus measurement temperature for specimens irradiated to a total fluence around $30 \times 10^{25} \mathrm{n} / \mathrm{m}^{2}[\mathrm{E}>0.1 \mathrm{MeV}]$. Dashed lines are to show the similarities of the mean CTE at the different irradiation temperatures. (d) Grade comparison of mean CTE change.

The low-fluence peak is thought to be due to the closure of the Mrozowski cracks that accommodate the initial densification [7]. The higher fluence behavior is still not verified with experimental evidence, but pose the following hypothetical processes. The rapid decrease after the peak is most likely a result of the formation of new cracks due to anisotropic grain growth becoming the dominant change microstructure feature. The plateau values are similar for all the irradiation temperatures, which suggests that the new accommodation features (pores, cracks, other) have a higher number density and/or larger size in the higher temperature specimens, which results in the same mean CTE over a $\sim 400^{\circ} \mathrm{C}$ temperature range. The plateau also suggests that the porosity that produces the volumetric swelling is not the 
accommodation feature, otherwise the CTE would continuously decrease with increasing fluence. The temperature difference in the plateau values in the normalized plot is a result of the differences in the preirradiation CTE at the different measurement temperatures. The changes to the CTE may be related to the differences between the in-crystal and pore generation microstructure changes that Haag [12] discussed for thermal conductivity losses. The only difference between the two grades (Figure 15d) is that the plateau values for G458A are higher than the same plateaus for G347A. The source of this difference is unknown, and speculation to the cause may lead back to differences caused by the filler source material.

The anisotropy ratio is determined from the ratio of the mean $\mathrm{CTE}$ at $500^{\circ} \mathrm{C}$ of the two orthogonal directions. The pre-irradiated material had an anisotropy ratio of 1.07, where the axial direction had the higher mean $\mathrm{CTE}$ at $500^{\circ} \mathrm{C}\left(4.48 \times 10^{-6} \mathrm{~K}^{-1}\right.$ axial vs. $4.18 \times 10^{-6} \mathrm{~K}^{-1}$ transverse $)$. There was no significant change in the anisotropy ratio at any of the irradiation conditions.

\subsection{COMPARISON WITH HISTORICAL RESULTS}

Little data is available regarding the neutron irradiation-induced changes in other fine-grained nuclear graphite grades. The only fine-grained grade that has been studied to fluences that are similar to this work is IG-110 [15, 32-34]. The earliest research was performed on IG-11, the non-purified precursor grade to IG-110 [33], and was shortly followed by an investigation of IG-110 [32, 34]. The primary focus of these studies were for use in the High Temperature Test Reactor (HTTR), hence most of the irradiation temperatures were above $575^{\circ} \mathrm{C}$ [32], $1000^{\circ} \mathrm{C}$ [33], and $800^{\circ} \mathrm{C}$ [34]. These experiments were also low fluence with values that approached levels of $7.5 \times 10^{25} \mathrm{n} / \mathrm{m}^{2}[\mathrm{E}>0.18 \mathrm{MeV}](6.7 \mathrm{dpa})[32], 2.5 \times 10^{25} \mathrm{n} / \mathrm{m}^{2}$ [EDN] (3.2 dpa) [33], and $2.83 \times 10^{25} \mathrm{n} / \mathrm{m}^{2}$ [E>0.18MeV] (2.5 dpa) [34]. The only work that has approached temperature and fluence levels that are similar to this work was irradiations performed at ORNL in the late 1980's [15], where the nominal design temperature was $600^{\circ} \mathrm{C}$ with a maximum damage of 25 dpa. Newer data from the INNOGRAPH/ARCHER irradiation program has been investigating the dimensional changes that occur in multiple iso-molded grades (grade is not reported) [35]. The $600^{\circ} \mathrm{C}$ and $750^{\circ} \mathrm{C}$ low-fluence IG- 110 results from Matsuo et al. [32, 34], and the $750^{\circ} \mathrm{C}$ results from INNOGRAPH/ARCHER [35] irradiations agree well with the G347A volume change for the high temperature regimes. The agreement of the results from this work and measurements on other grades is shown in Figure 16. The results from Ishiyama et al. [15] are not in agreement with the results for G347A, but there are multiple concerns regarding the validity of the reported temperature and the volume changes in this previous work. 


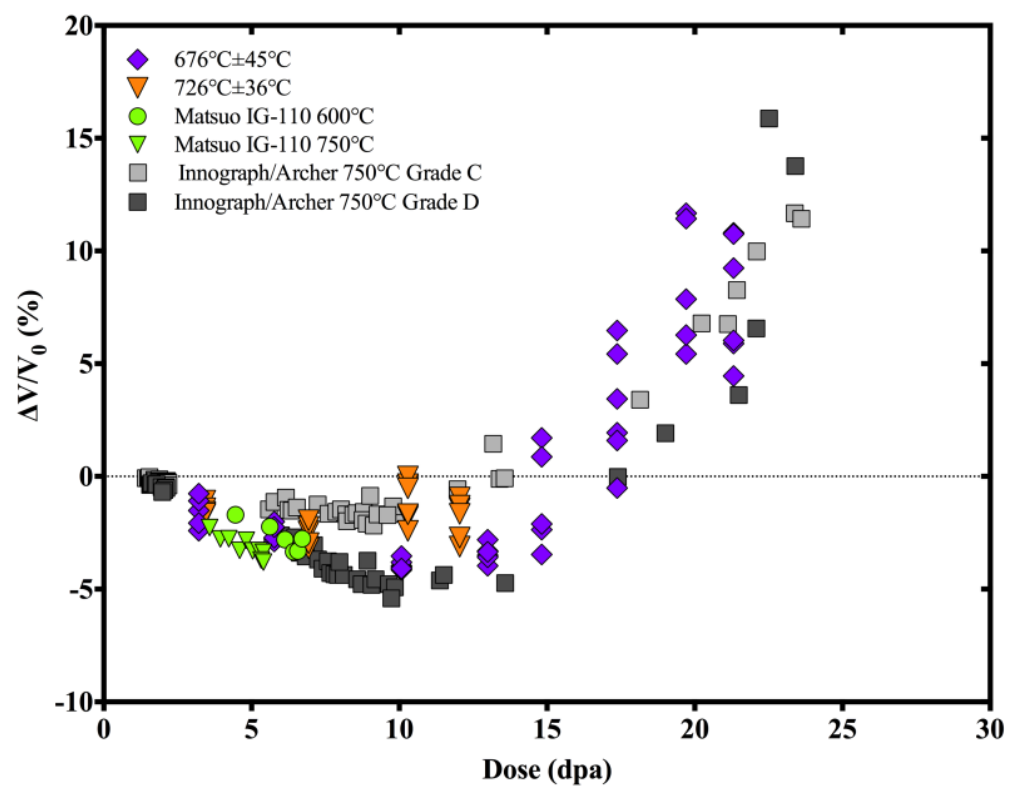

Figure 16. Comparison of G347A results with results on IG-110 (Matsuo [32]) and two unidentified isomolded graphite grades (INNOGRAPH/ARCHER [35]) at similar irradiation temperatures.

The IG-110 irradiation results [15] are suspect because there is uncertainty in the irradiation temperature, and the disassembly difficulty suggests the specimens did not experience unrestricted dimensional change. The specimens were irradiated in the HTK-7 experiment at ORNL. The specimens were irradiated in a cylindrical target rod, where 64 graphite specimens (of multiple grades) were stacked on top of one another along the height of the HFIR core [36]. Alignment of the specimens in the irradiation rig was achieved with a POCO graphite spline that went down the center hole of the specimens. No active temperature measurement and control was utilized; instead the final temperature was to be determined from eight silicon carbide $(\mathrm{SiC})$ temperature monitors that were placed down the center of the POCO graphite spline. The gap between the outer diameter of the specimens and the aluminum wall was the only thermal insulator to keep the specimens at the desired temperature. The thickness of the gas gap and fill gas type was determined with a one-dimensional heat transfer model to achieve this desired temperature. The design temperature of HTK-7 was $600^{\circ} \mathrm{C}$ and the geometry of the experiment suggests that the fill gas was argon. Argon gas has a high thermal resistivity, which makes the temperature more susceptible to minute changes in the gap. Specimen dimensions were measured before irradiation, but there is no data on the inner hole diameter.

There are two questions about the HTK-7 results: 1) was irradiation temperature $600^{\circ} \mathrm{C}$ ? and 2) was specimen dimensional change un-restricted? The temperature uncertainty is because the reported temperature of $600^{\circ} \mathrm{C}$ was the design temperature, but the actual temperature was not confirmed with analysis of the passive thermometry ${ }^{1}$. During the irradiation, a combination of the SiC swelling and POCO contraction caused the $\mathrm{SiC}$ pieces to become jammed in the spline, and all but one of the $\mathrm{SiC}$ pieces broke during disassembly. The uncertainty as to whether the specimens experienced un-restricted

\footnotetext{
${ }^{1}$ Private communication with Dr. Timothy D. Burchell.
} 
dimensional/volume change is because during unloading after irradiation it was noted that many of the specimens underwent enough contractions that the specimens were clamped onto the POCO spline ${ }^{1}$. Lastly, without having the pre-irradiation inner hole diameter it is not possible to state for certain the net volume change.

\section{CONCLUSIONS}

Fine-grain graphite grade G347A (from Tokai Carbon Co., Ltd.) was irradiated in the HFIR at ORNL to a maximum neutron fluence of $40 \times 10^{25} \mathrm{n} / \mathrm{m}^{2}$ [E>0.1MeV]. The actual specimen temperatures ranged from $290^{\circ} \mathrm{C}-800^{\circ} \mathrm{C}$, and the specimens were grouped according to design temperature that resulted in temperature ranges of $395^{\circ} \mathrm{C} \pm 62^{\circ} \mathrm{C}, 459^{\circ} \mathrm{C} \pm 37^{\circ} \mathrm{C}, 535^{\circ} \mathrm{C} \pm 33^{\circ} \mathrm{C}, 684^{\circ} \mathrm{C} \pm 41^{\circ} \mathrm{C}, 738^{\circ} \mathrm{C} \pm 43^{\circ} \mathrm{C}$. The temperature ranges had turn-around fluences of $18,15,14,10$, and $10 \times 10^{25} \mathrm{n} / \mathrm{m}^{2}[\mathrm{E}>0.1 \mathrm{MeV}]$, respectively. The set of temperature and fluence levels provided insight into different property changes and how irradiation temperature effects these changes for this grade.

The volume change provided behavior expected for graphite where the maximum shrinkage was smaller, and a lower fluence was necessary to reach turn-around, for the higher irradiation temperatures. Similar behavior has been observed in previous work $[3,5-9,12,16]$. The dimensional change of the specimens did provide an unexpected behavior, where there was significant difference between the two discrete orthogonal directions. G347A has an isotropy ratio of 1.07, which signifies a 7\% difference of the mean CTE of these two directions. Whereas there was a $30 \%$ difference in the fluence where the different orientated specimen dimensions return to pre-irradiation values.

The Young's and shear moduli displayed a parabolic fluence dependence, which is a slightly different trend than was proposed previously for graphite $[1,3,6,7,9,12,13,15]$. This difference may be an artifact due to a lack of low-fluence measurements or a difference in the process that causes the lowfleunce change in larger-grained graphites. The electrical resistivity shows a rapid increase, which occurs in other graphites $[1,3,7,12]$, but also observed in this work is a second increase in resistivity when specimen volume surpasses the pre-irradiation volume. The change of the equibiaxial strength had a parabolic dependence on fluence, but showed that the power-law dependence on the square root of the Young's modulus is only applicable before turn-around.

The neutron irradiation-induced changes to the thermal properties also follow trends similar to that observed in literature. The room temperature thermal conductivity underwent a rapid decrease, which has been shown previously $[1,3,6,7,12,15]$, but the new trend has shown a continued decrease after the initial drop rather than the plateau behavior observed previously. This work also provided insight into the thermal conductivity changes at the irradiation temperature, which have not been extensively studied in the past. The results showed that the thermal conductivity is nearly identical at a given neutron fluence for all the temperatures investigated in this work. This suggests that the thermal conductivity loss due to neutron irradiation is controlled by microstructure changes affecting the phonon scattering and that the Umklapp effect at high temperature becomes negligible. The mean CTE shows an initial increase followed by a decrease to a plateau at a reduced value that is similar to historical results $[3,5,7,9,12]$. The newer trend is that the plateau value is similar for all irradiation temperatures, which suggests that there is more irradiation-produced accommodation porosity created at the higher irradiation temperatures. 
Limited specimens of grade G458A were included for irradiation to investigate the behavioral differences between the two grades. The volume and thermal conductivity loss were similar between the grades, but for the other properties G458A presented: a greater anisotropy of the dimensional change, smaller change to the Young's modulus, and the mean CTE change was larger at all fluences. Additional comparison of G347A with historical results for another iso-molded fine-grained graphite IG-110 showed relatively good agreement with low-fluence results [32], but the disagreement with high-fluence results is most likely a result of uncertainty of irradiation temperature of the literature values [15].

The pre-irradiation properties of G347A agree with this grade being classified as a "Isomolded, Isotropic - High Purity" grade, according to ASTM D7219-08 [17]. The results from this work show that G347A has similar neutron irradiation-induced property changes to that of previously investigated fine-grained nuclear grade IG-110 and other unknown isostatic pressed grades.

\section{ACKNOWLEDGEMENTS}

This program would not have been completed without the expertise and input from numerous persons throughout the laboratory. Special notice needs to be given to the technicians of the LAMDA laboratory: M.Williams, P.Tedder, S.Curlin, D.Lewis, M.McAllister, W.Comings, B.Eckhart, A.Clark, and W.D.Porter.

This research was performed at the Oak Ridge National Laboratory (ORNL) and sponsored by Tokai Carbon Co., Ltd. under the Material Science and Technology Division, Work-for-Others (WFO) Program, IAN: 16B630901, and DOE agreement: NFE-09-02345, with the U.S. Department of Energy.

A portion of this research at ORNL's High Flux Isotope Reactor was sponsored by the Scientific User Facilities Division, Office of Basic Energy Sciences, U.S. Department of Energy. Oak Ridge National Laboratory is managed by UT-Battelle, LLC under Contract No. DE-AC05-00OR22725 for the U.S. Department of Energy.

\section{REFERENCES}

1. Nightingale, R.E., "Nuclear Graphite", 1962, New York, Academic Press.

2. Kelly, B.T., D. Jones, and A. James, "Irradiation damage to pile grade graphite at $450^{\circ} \mathrm{C}$, Journal of Nuclear Materials, 7, (1962) 279-291.

3. Bridge, H., B.T. Kelly, and P.T. Nettley, "Effect of high-flux fast-neutron irradiation on the physical properties of graphite", Carbon, 2, (1964) 83-93.

4. Simmons, J.H.W., B.T. Kelly, P.T. Nettley, and W.N. Reynolds, The Irradiation Behavior of Graphite, in Third United Nations Internatinal Conference on the Peaceful Uses of Atomic Energy, 1964, United Kingdon, p. Paper \#163.

5. Kelly, B.T., W.H. Martin, and P.T. Nettley, "Dimensional Changes in Polycrystalline Graphites under Fast-Neutron Irradiation", Philosophical Transactions of the Royal Society A, 260, (1966) 51-71.

6. Nettley, P.T., J.E. Brocklehurst, W.H. Martin, and J.H.W. Simmons, "Irradiation Experience with Isotropic Graphite", Presented at Symposium on Advanced and High Temperature Gas-Coolet Reactors, Julich, October 21-25, 1968. 
7. Simmons, J.H.W., "Radiation damage in graphite", International Series of Monographs in Nuclear Energy, Vol. 102, 1965, Oxford, New York, Pergamon Press.

8. $\quad$ Kelly, B.T., "Physics of Graphite", 1981, London, Applied Science Publishers.

9. Burchell, T.D. and W.P. Eatherly, "The effects of radiation damage on the properties of GraphNOL N3M", Journal of Nuclear Materials, 179-181, Part 1, (1991) 205-208.

10. "Irradiation Damage in Graphite due to Fast Neutrons in Fission and Fusion Systems", (2000). IAEA-TECDOC-1154.

11. Burchell, T.D., "Neutron Irradiation Damage in Graphite and Its Effects on Properties", Presented at International Carbon Conference CARBON 2002, Beijing, China, September 15-20, 2002.

12. Haag, G., "Properties of ATR-2E Graphite and Property Changes due to Fast Neutron Irradiation", Berichte des Forschungszentrums J/'fclich\, Vol. 4183\, 2005, J'fclich\, FZJ, Institut $\mathrm{fl}$ 'fcr Sicherheitsforschung und Reaktortechnikl.

13. Burchell, T.D. and L.L. Snead, "The effect of neutron irradiation damage on the properties of grade NBG-10 graphite", Journal of Nuclear Materials, 371, (2007) 18-27.

14. Burchell, T.D., "4.10 - Radiation Effects in Graphite", in Comprehensive Nuclear Materials, R.J.M. Konings, Editor, 2012, Elsevier, Oxford, p. 299-324.

15. Ishiyama, S., T.D. Burchell, J.P. Strizak, and M. Eto, "The effect of high fluence neutron irradiation on the properties of a fine-grained isotropic nuclear graphite", Journal of Nuclear Materials, 230, (1996) 1-7.

16. Kelly, B.T. and T.D. Burchell, "Structure-related property changes in polycrystalline graphite under neutron irradiation", Carbon, 32, (1994) 499-505.

17. ASTM D7219-08, 2008, "Standard Specification for Isotropic and Near-Isotropic Nuclear Graphites", ASTM International, West Conshohocken, PA, DOI: 10.1520/D7219-08R14, http://www.astm.org/.

18. ASTM C559-90, 2010, "Standard Test Method for Bulk Density by Physical Measurements of Manufactured Carbon and Graphite Articles", ASTM International, West Conshohocken, PA, DOI: 10.1520/C0559-90R10, http://www.astm.org/.

19. ASTM C838-96, 2010, "Standard Test Method for Bulk Density of As-Manufactured Carbon and Graphite Shapes", ASTM International, West Conshohocken, PA, DOI: 10.1520/C0838-96, http://www.astm.org/.

20. ASTM C1259-14, 2009, "Standard Test Method for Dynamic Young's Modulus, Shear Modulus, and Poisson's Ratio for Advanced Ceramics by Impulse Excitation of Vibration", ASTM International, West Conshohocken, PA, DOI: 10.1520/C1259, http://www.astm.org/.

21. ASTM E228-11, 2011, "Standard Test Method for Linear Thermal Expansion of Solid Materials With a Push-Rod Dilatometer", ASTM International, West Conshohocken, PA, DOI: 10.1520/E0228-95, http://www.astm.org/.

22. ASTM E1461-13, 2013, "Standard Test Method for Thermal Diffusivity by the Flash Method", ASTM International, West Conshohocken, PA, DOI: 10.1520/E1461, http://www.astm.org/. 
23. ASTM C611-98, 2010, "Standard Test Method for Electrical Resistivity of Manufactured Carbon and Graphite Articles at Room Temperature", ASTM International, West Conshohocken, PA, DOI: 10.1520/C0611-98R10E01, http://www.astm.org/.

24. ASTM C1499-09, 2013, "Standard Test Method for Monotonic Equibiaxial Flexural Strength of Advanced Ceramics at Ambient Temperature", ASTM International, West Conshohocken, PA, DOI: 10.1520/C1499, http://www.astm.org/.

25. Campbell, A.A., W.D. Porter, Y. Katoh, and L.L. Snead, "Method for Analyzing Passive SiC Thermometry with a Continuous Dilatometer to Determine Irradiation Temperature", NIMB, 370, (2016) 49-58.

26. "Carbon Materials for Advanced Technologies", ed. T.D. Burchell, 1999.

27. Haag, G., "Dimensional Changes of Some Iso-Graphites in Comparison with Extruded of Moulded Graphites", Presented at International Nuclear Graphite Specialist Meeting (INGSM-4), Marugame, Japan, September 13-16, 2003.

28. ASTM C709-09, 2009, "Standard Terminology Relating to Manufactured Carbon and Graphite", ASTM International, West Conshohocken, PA, 10.1520/C0709-09,

29. Yoda, S., M. Eto, K. Tanaka, and T. Oku, "Effects of Oxidation on Compressive Deformation Behavior of Nuclear-Grade Isotropic Graphite", Carbon, 23, (1985) 33-38.

30. Kennedy, C.R., W.H. Cook, and W.P. Eatherly, Results of Irradiation Creep Testing Graphite at $900^{\circ} \mathrm{C}$, in Extended Abstracts of the 13th Biennial Conference on Carbon, 1977, American Carbon Society, Irving, CA, p. 342-343.

31. Snead, L.L., S.J. Zinkle, and D.P. White, "Thermal conductivity degradation of ceramic materials due to low temperature, low dose neutron irradiation", Journal of Nuclear Materials, 340, (2005) 187-202.

32. Matsuo, H., S. Nomura, H. Imai, T. Oku, and M. Eto, "Effects of High Temperature Neutron Irradiation on the Physical, Chemical and Mechanical Properties of Fine-Grained Isotropic Graphite", (1987). IAEA Specialist Meeting on Graphite Component Structural Design (held in JAERI Tokai, Japan. September 8-11, 1986), JAERI-M 86-192.

33. Nomura, S., J. Shimokawa, Y. Sasaki, T. Oku, H. Matsuo, M. Eto, Y. Fukuda, and K. Fujisaki, "Effects of Neutron Irradiation on Physical and Mechanical Properties SM 1-24 and IG-11 Graphites; Report on JAERI/KFA Julich Graphite Irradiation Experiment HFR GG 14", (1979). JAERI-M 8068.

34. Matsuo, H., "Effects of high temperature neutron irradiation on dimensional changes and physical properties of nuclear graphites for HTGR", (1988). JAERI-M 87-207.

35. Heijna, M., "The INNOGRAPH-1C low dose irradiation experiment extending the HTR graphite materials properties curves at $750^{\circ} \mathrm{C} "$, Presented at 15 th International Nuclear Graphite Specialist Meeting (INGSM-15), Hangzhou, China, September 15-18, 2014.

36. Homan, F.J. and P.R. Kasten, "Gas-Cooled Reactor Programs, High-Temperature Gas-Cooled Reactor Base-Technology Program Annual Progress Report for Period Ending December 31, 1977", (1978). ORNL-5412. 